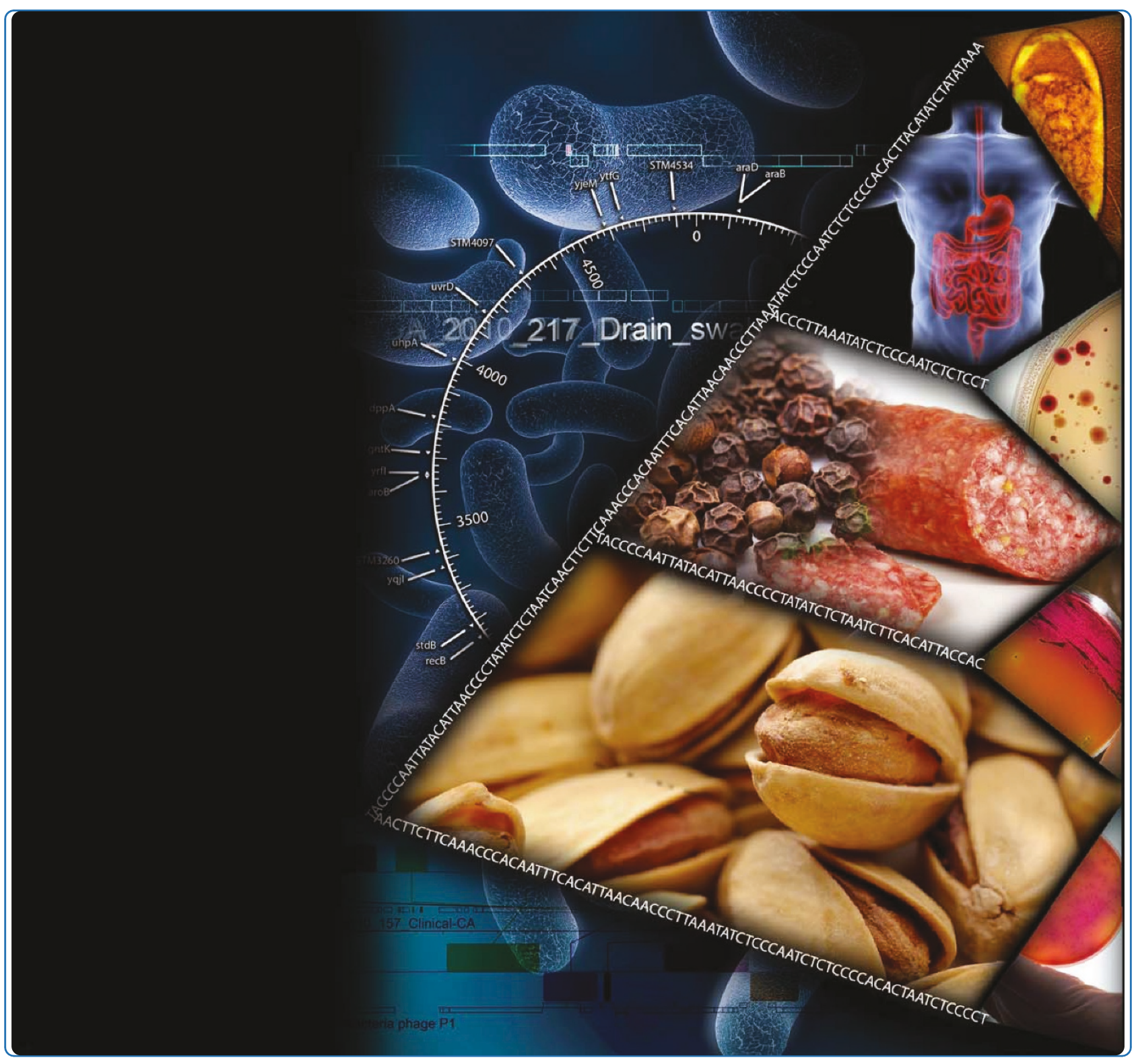

High resolution clustering of Salmonella enterica serovar Montevideo strains using a nextgeneration sequencing approach

Allard et al. 


\title{
High resolution clustering of Salmonella enterica serovar Montevideo strains using a next- generation sequencing approach
}

Marc W Allard ${ }^{1 *}$, Yan Luo ${ }^{2}$, Errol Strain ${ }^{2}$, Cong Li ${ }^{1}$, Christine E Keys ${ }^{1}$, Insook Son ${ }^{1}$, Robert Stones ${ }^{3}$, Steven M Musser ${ }^{1}$ and Eric W Brown ${ }^{1}$

\begin{abstract}
Background: Next-Generation Sequencing (NGS) is increasingly being used as a molecular epidemiologic tool for discerning ancestry and traceback of the most complicated, difficult to resolve bacterial pathogens. Making a linkage between possible food sources and clinical isolates requires distinguishing the suspected pathogen from an environmental background and placing the variation observed into the wider context of variation occurring within a serovar and among other closely related foodborne pathogens. Equally important is the need to validate these high resolution molecular tools for use in molecular epidemiologic traceback. Such efforts include the examination of strain cluster stability as well as the cumulative genetic effects of sub-culturing on these clusters. Numerous isolates of $\mathrm{S}$. Montevideo were shot-gun sequenced including diverse lineage representatives as well as numerous replicate clones to determine how much variability is due to bias, sequencing error, and or the culturing of isolates. All new draft genomes were compared to $34 \mathrm{~S}$. Montevideo isolates previously published during an NGS-based molecular epidemiological case study.

Results: Intraserovar lineages of S. Montevideo differ by thousands of SNPs, that are only slightly less than the number of SNPs observed between S. Montevideo and other distinct serovars. Much less variability was discovered within an individual S. Montevideo clade implicated in a recent foodborne outbreak as well as among individual NGS replicates. These findings were similar to previous reports documenting homopolymeric and deletion error rates with the Roche 454 GS Titanium technology. In no case, however, did variability associated with sequencing methods or sample preparations create inconsistencies with our current phylogenetic results or the subsequent molecular epidemiological evidence gleaned from these data.

Conclusions: Implementation of a validated pipeline for NGS data acquisition and analysis provides highly reproducible results that are stable and predictable for molecular epidemiological applications. When draft genomes are collected at $15 x-20 x$ coverage and passed through a quality filter as part of a data analysis pipeline, including sub-passaged replicates defined by a few SNPs, they can be accurately placed in a phylogenetic context. This reproducibility applies to all levels within and between serovars of Salmonella suggesting that investigators using these methods can have confidence in their conclusions.
\end{abstract}

\footnotetext{
* Correspondence: Marc.Allard@fda.hhs.gov

'Office of Regulatory Science, Center for Food Safety \& Applied Nutrition, U. S. Food \& Drug Administration, 5100 Paint Branch Parkway, College Park, MD 20740, USA

Full list of author information is available at the end of the article
} 


\section{Background}

Foodborne pathogens cause an estimated 9.4 million human illnesses in the U.S. each year, resulting in nearly 60,000 hospitalizations and over 1,300 deaths [1-4]. Salmonella enterica remains one of the most devastating of these foodborne pathogens with $11 \%$ of all food related deaths being attributed from exposure to this bacterium [4]. The genus Salmonella comprises two species, $S$. enterica and S. bongori, both of which have been found in the food supply. Six subspecies of S. enterica have been described (I-IIIa, IIIb, IV, and VI) that can be found in a variety of mammalian and non-mammalian hosts including humans, cattle, birds, turtles, and snakes. Most non-typhoidal salmonellosis cases in mammals, including humans, come from over 1700 different Salmonella group (subspecies) I serovars. While several group I serovars such as $S$. Typhimurium and $S$. Enteritidis have been studied more widely, the genetic and phylogenetic diversity defining many of the important group I Salmonellae remains poorly understood.

One of these serovars, Salmonella enterica subsp. enterica serovar Montevideo (i.e., S. Montevideo) is one of the top ten most common serovars associated with contaminated foods. This serovar was recently associated with a Pistachio recall in 2008, and more recently, with contamination of certain pet treats http://www.fda. gov/Safety/Recalls/ucm218039.htm. Moreover, this serovar has been implicated in contamination events involving numerous meat and cheese products http://www. outbreakdatabase.com/site/search/?tag=s. +montevideo. More recently, a strain of $S$. Montevideo was linked to more than 240 illnesses in 38 states after being found in red and black pepper used in the production of contaminated Italian-style spiced meats [[5], http://www. cdc.gov/Salmonella/montevideo/montevideo_timeline2. pdf]. It is important to note that many of these highly clonal strains of $S$. Montevideo often confound epidemiological investigations because pulsed-field gel electrophoresis (PFGE) is unable to always distinguish outbreak-related strains from other genetically similar strains unassociated with the same outbreak. Strains of this nature often retain common PFGE patterns despite their sporadic or more historic origins.

The accurate subtyping and subsequent clustering of isolates of a bacterium associated with a foodborne outbreak event is essential for successful investigation and eventual traceback to a specific food or environmental source [6-12]. In this regard, PFGE continues to deliver useful genetic typing information by facilitating public health investigations for nearly two decades. In certain cases, however, highly clonal strains, common among some group I Salmonellae, confound epidemiological investigations because PFGE provides limited genetic differentiation of these strains. That is this approach often lacks the resolution for differentiating highly clonal bacterial isolates. In response to such events, federal public health and food safety laboratories are exploring next-generation sequencing (NGS) to define complex outbreak scenarios. NGS refers to highly parallel robotic genomic sequencers, like Roche 454 GS Titanium technology, that are being used to accomplish the whole genome sequencing (WGS) of a bacterial pathogen.

NGS is contributing long anticipated solutions to what were once viewed as insurmountable challenges, in the genetic analysis of bacterial pathogens [13-16]. Complete genome sequences from multiple bacterial strains can now be collected and analyzed in just a few days [17], underscoring the future potential of this technology as a molecular epidemiological tool to assist in foodborne outbreak investigations. Recent examples in the literature illustrate the ability of NGS to discern the highresolution genetic relatedness and unrelatedness of otherwise indistinguishable isolates based on the microevolutionary genetic change that define clinical isolates, outbreak isolates found in foods, and their environmental counterparts [18-20].

These novel applications of NGS are buttressed by a massive influx of new genomic data, producing new discoveries about the critical genes that define particular pathogens, and important genomic changes associated with pathogenicity, antibiotic resistance, and unique carbon source usage $[19,20]$. However, the race to sequence more bacterial pathogen genomes must be tempered by the realities and rigor of formal methods validation processes for tools deployed in epidemiological investigation http://www.fda.gov/MedicalDevices/DeviceRegulationandGuidance/GuidanceDocuments/ucm077862.htm. This validation process is not only required for regulatory action by federal and state laboratories whose duty it is to conduct these tests, but these general procedures must be applied if the technology is to meet scientific admissibility requirements in a legal setting. Although still being developed, historical paradigms exist for the validation of sequence data. Capillary electrophoresis (CE) sequencing, for example, has been a standard technology since the early 1990s, and its accuracy has proven to be sufficient so that $C E$ is now widely applied by a variety of federal agencies engaged in activities spanning forensic and molecular epidemiologic analyses $[21,22]$.

Herein, we demonstrate the value of NGS in defining the diversity of Salmonella Montevideo using a representative set of environmental, laboratory, food, and clinical strains, some of which have been associated repeatedly with contamination events in several food sources [5]. Here, our analyses using NGS data provided 
far greater resolving power than previously available from other techniques. This information was essential to reconstructing both the deep phyletic relationships of this serovar and terminal relationships among highly clonal S. Montevideo isolates. Moreover, the clonally derived outbreak cluster of $S$. Montevideo were defined by a few single nucleotide polymorphisms (SNPs) while more geographically or temporally removed isolates showed tens to thousands of SNP differences. Additionally, NGS technology revealed considerable genomic stability and high reproducibility for SNP targets used in the clustering of closely related isolates within an important and emerging serovar of Salmonella enterica.

\section{Results}

NGS reveals substantial intra-serovar diversity within Salmonella Montevideo

In order to explore the evolutionary genetic diversity of Salmonella Montevideo, NGS analysis was performed on 47 strains of this serovar (Table 1). This included assembling the raw reads to form contigs of overlapping sequence, annotating those contigs to determine which genes were present, and then determining homology among genes and aligning and concatenating those genetic elements for population and phylogenetic analyses. Roche-Titanium whole-genome shotgun sequencing technology [23,24] provided 15-20× coverage for each genome reported, and downstream contig assembly and sequence alignment provided over 4.5-5 mbp of assembled contigs for each isolate. Additional data filtering yielded 72,063 variable SNP sites of which 63,987 were identified as parsimony informative (i.e., SNPs shared by two or more strains in the alignment) and subjected to phylogenetic analysis on the FDA bioinformatics, Linux based computer cluster using likelihood and parsimony methods. The resultant evolutionary tree derived from the informative SNP data yielded two important observations (Figure 1). First, S. Montevideo formed a monophyletic group of strains phylogenetically distinct from other neighboring serovars including $S$. Schwarzengrund, S. Pomona, and S. Javiana. Second, S. Montevideo strains partitioned into four disparate clades (designated I-IV), several of which were defined by a mixture of both natural and laboratory isolates. Clade III, for example, comprised a clinical isolate associated with tomato (206_Clinical) as well as a single strain (160_Clinical_FL) from the widely characterized subspecies I Salmonella Reference collection, SARB [25].

Pairwise SNP variation between these four $S$. Montevideo lineages is listed in Table 2. Intra-serovar SNP diversity was remarkable among the four diverged $S$. Montevideo genome lineages ranging from 17,600 SNPs (clade I/clade II) to $23,800 \mathrm{SNPs}$ (clade II/clade IV). This latter distance was astonishing given that SNP divergence between $S$. Montevideo lineage I and $S$. Pomona, a different group I serovar, falls well within this range (i.e., 22,700 SNPs). In addition to the substantial SNP-based diversity noted among $S$. Montevideo lineages, genome size also fluctuated widely within this serovar (Figure 2). That is, genome length ranged from less than 4.45 million bp to about 4.75 million bp, sorting largely along intra-serovar clade divisions revealed in the phylogenetic tree (Figure 1). Most of the observed genome size differences appear to be due to the presence or absence of phage elements. The CA clinical isolate 157, for example, is bigger than the outbreak cluster in general due to phage D6. In addition, S. Montevideo strain 163 appears to be enlarged due to insertion of a plasmid pRA1, while strain 206 retains an uncharacterized phage-like sequence and elements of the SPI-7 pathogenicity island. Conversely, two smaller S. Montevideo genomes, 162 and 205, appear to be missing the putative Salmonella phage sequence relative to the outbreak cluster (i.e., clade IV, Figure 1). Akin to findings reported previously on the stress-induced acquisition and loss of phage elements in the Salmonella genome [26], these data signal an important role for insertions and deletions in the diversification of specific clones of $S$. Montevideo, and, taken together with the above SNP findings, point to a serovar of non-typhoidal Salmonella comprised of several genomically diverged and phylogenetically distinct clones [27-29].

\section{NGS phylogenetically differentiates a clonal lineage of Salmonella Montevideo}

The importance of NGS in ascertaining high-resolution phylogenetic and molecular epidemiological histories of infectious outbreak clones of bacterial pathogens has recently been noted $[18,20]$. In the current study, NGS was applied for reconstructing the detailed evolutionary genetic structure of an individual clone of $S$. Montevideo that is largely indistinguishable using PFGE. Specifically, NGS analysis was applied to a set of $S$. Montevideo isolates either associated with or genetically homologous to a food contamination event of spiced Italian-style meats in the U.S. in 2009 and 2010 http:// www.cdc.gov/Salmonella/montevideo/index.html. We reported previously on the success of NGS for distinguishing some of these isolates from other clonally related isolates unassociated with this spiced-meat $S$. Montevideo outbreak [5]. Herein, we combined the genomes of 34 highly homogeneous $S$. Montevideos from food, environmental, and clinical sources from this spiced-meat outbreak with 24 newly sequenced $(\sim 15 \mathrm{X})$ $S$. Montevideo genomes derived from clinical-food matches associated with the same spiced-meat contamination event. As an important control, historical $S$. Montevideos from within this clone were included that 
Table 1 List of isolates sequenced for comparison.

\begin{tabular}{|c|c|c|c|c|c|c|c|}
\hline $\begin{array}{c}\text { FDA } \\
\text { Name }\end{array}$ & Tree Label & Locus Tag & GenBank & SRA & $\begin{array}{c}\text { NCBI } \\
\text { BioProject }\end{array}$ & Biosample & Full Name \\
\hline 142 & 142_Pistachio_3 & SEEM315 & AESH00000000 & $\begin{array}{l}\text { SRX101634, } \\
\text { SRX118696, } \\
\text { SRX119982 }\end{array}$ & 46535 & 710595 & $\begin{array}{c}\text { Salmonella enterica subsp. } \\
\text { enterica serovar Montevideo } \\
\text { str. } 315996572\end{array}$ \\
\hline 144 & 144_Black_Pepper_6 & SEEM971 & AESI00000000 & $\begin{array}{l}\text { SRX101636, } \\
\text { SRX119983, } \\
\text { SRX118697 }\end{array}$ & 46539 & 710606 & $\begin{array}{c}\text { Salmonella enterica subsp. } \\
\text { enterica serovar Montevideo } \\
\text { str. 495297-1 }\end{array}$ \\
\hline 145 & 145_Black_Pepper_5 & SEEM973 & AESJ00000000 & SRX101642 & 46541 & 710617 & $\begin{array}{c}\text { Salmonella enterica subsp. } \\
\text { enterica serovar Montevideo } \\
\text { str. } 495297-3\end{array}$ \\
\hline 146 & 146_Black_Pepper_7 & SEEM974 & AESK00000000 & SRX101643 & 46543 & 710624 & $\begin{array}{c}\text { Salmonella enterica subsp. } \\
\text { enterica serovar Montevideo } \\
\text { str. } 495297-4\end{array}$ \\
\hline 147 & 147_Black_Pepper_3 & SEEM201 & AESL00000000 & SRX101644 & 46545 & 710625 & $\begin{array}{c}\text { Salmonella enterica subsp. } \\
\text { enterica serovar Montevideo } \\
\text { str. 515920-1 }\end{array}$ \\
\hline 148 & 148_Black_Pepper_4 & SEEM202 & AESM00000000 & $\begin{array}{l}\text { SRX101645, } \\
\text { SRX118768 }\end{array}$ & 46547 & 710626 & $\begin{array}{c}\text { Salmonella enterica subsp. } \\
\text { enterica serovar Montevideo } \\
\text { str. } 515920-2\end{array}$ \\
\hline 155 & 155_Clinical_NC_4 & SEEM054 & AESO00000000 & $\begin{array}{l}\text { SRX101647, } \\
\text { SRX118769 }\end{array}$ & 46903 & 710628 & $\begin{array}{c}\text { Salmonella enterica subsp. } \\
\text { enterica serovar Montevideo } \\
\text { str. NC_MB110209-0054 }\end{array}$ \\
\hline 156 & 156_Clinical_OH_3 & SEEM675 & AESP00000000 & $\begin{array}{l}\text { SRX101648, } \\
\text { SRX119984, } \\
\text { SRX118770 }\end{array}$ & 46905 & 710629 & $\begin{array}{c}\text { Salmonella enterica subsp. } \\
\text { enterica serovar Montevideo } \\
\text { str. OH_2009072675 }\end{array}$ \\
\hline 157 & 157_Clinical_CA & SEEM965 & AESQ00000000 & $\begin{array}{l}\text { SRX101649, } \\
\text { SRX119443, } \\
\text { SRX118771 }\end{array}$ & 46907 & 710596 & $\begin{array}{c}\text { Salmonella enterica subsp. } \\
\text { enterica serovar Montevideo } \\
\text { str. CASC_09SCPH15965 }\end{array}$ \\
\hline 158 & 158_Clinical_MD & SEEM507 & AETA00000000 & SRX101650 & 49405 & 710597 & $\begin{array}{l}\text { Salmonella enterica subsp. } \\
\text { enterica serovar Montevideo } \\
\text { str. MD_MDA09249507 }\end{array}$ \\
\hline 160 & 160_Clinical_FL* & SEEM031 & AESR00000000 & SRX105725 & 46911 & 754243 & $\begin{array}{c}\text { Salmonella enterica subsp. } \\
\text { enterica serovar Montevideo } \\
\text { str. SARB31 }\end{array}$ \\
\hline 161 & 161_Clinical_1993* & SEEM710 & AESS00000000 & SRX105759 & 46913 & 754295 & $\begin{array}{c}\text { Salmonella enterica subsp. } \\
\text { enterica serovar Montevideo } \\
\text { str. ATCC BAA710 }\end{array}$ \\
\hline 162 & 162_Reference* & SEEM010 & AEST00000000 & SRX105760 & 46915 & 754296 & $\begin{array}{c}\text { Salmonella enterica subsp. } \\
\text { enterica serovar Montevideo } \\
\text { str. LQC } 10\end{array}$ \\
\hline 163 & 163_Clinical_GA* & SEEM030 & AESU00000000 & SRX105761 & 46917 & 754297 & $\begin{array}{c}\text { Salmonella enterica subsp. } \\
\text { enterica serovar Montevideo } \\
\text { str. SARB30 }\end{array}$ \\
\hline 204 & 204_Chicken & SEEM19N & AESV00000000 & $\begin{array}{l}\text { SRX101465, } \\
\text { SRX118774 }\end{array}$ & 48457 & 710598 & $\begin{array}{c}\text { Salmonella enterica subsp. } \\
\text { enterica serovar Montevideo } \\
\text { str. } 19 \mathrm{~N}\end{array}$ \\
\hline 205 & 205_Soup* & SEEM29N & AESW00000000 & SRX105762 & 48459 & 754298 & $\begin{array}{c}\text { Salmonella enterica subsp. } \\
\text { enterica serovar Montevideo } \\
\text { str. } 29 \mathrm{~N}\end{array}$ \\
\hline 206 & 206_Clinical* & SEEM42N & AESX00000000 & SRX105763 & 48461 & 754299 & $\begin{array}{c}\text { Salmonella enterica subsp. } \\
\text { enterica serovar Montevideo } \\
\text { str. } 42 \mathrm{~N}\end{array}$ \\
\hline 207 & 207_Sunflower* & SEEM41H & AESY00000000 & $\begin{array}{l}\text { SRX105764, } \\
\text { SRX105765 }\end{array}$ & 49127 & 754300 & $\begin{array}{c}\text { Salmonella enterica subsp. } \\
\text { enterica serovar Montevideo } \\
\text { str. } 4441 \mathrm{H}\end{array}$ \\
\hline 209 & 209_Romaine & SEEM801 & AESZ00000000 & SRX101467 & 49129 & 710599 & $\begin{array}{c}\text { Salmonella enterica subsp. } \\
\text { enterica serovar Montevideo } \\
\text { str. 81038-01 }\end{array}$ \\
\hline 210 & 210_Mozzarella & SEEM877 & AETB00000000 & SRX101651 & 49987 & 710600 & $\begin{array}{c}\text { Salmonella enterica subsp. } \\
\text { enterica serovar Montevideo } \\
\text { str. } 414877\end{array}$ \\
\hline
\end{tabular}


Table 1 List of isolates sequenced for comparison. (Continued)

\begin{tabular}{|c|c|c|c|c|c|c|c|}
\hline 211 & 211_Perch & SEEM867 & AETC00000000 & $\begin{array}{l}\text { SRX101652, } \\
\text { SRX118775 }\end{array}$ & 49989 & 710601 & $\begin{array}{c}\text { Salmonella enterica subsp. } \\
\text { enterica serovar Montevideo } \\
\text { str. } 366867\end{array}$ \\
\hline 212 & 212_Sea_Trout & SEEM180 & AETD00000000 & $\begin{array}{l}\text { SRX101653, } \\
\text { SRX119985, } \\
\text { SRX118776 }\end{array}$ & 49991 & 710602 & $\begin{array}{c}\text { Salmonella enterica subsp. } \\
\text { enterica serovar Montevideo } \\
\text { str. } 413180\end{array}$ \\
\hline 213 & 213_King Fish & SEEM600 & AETE00000000 & SRX101659 & 49993 & 710603 & $\begin{array}{c}\text { Salmonella enterica subsp. } \\
\text { enterica serovar Montevideo } \\
\text { str. } 446600\end{array}$ \\
\hline 214 & 214_Black_Pepper_1 & SEEM581 & AETF00000000 & SRX101660 & 49995 & 710604 & $\begin{array}{c}\text { Salmonella enterica subsp. } \\
\text { enterica serovar Montevideo } \\
\text { str. 609458-1 }\end{array}$ \\
\hline 215 & 215_Red_Pepper_2 & SEEM501 & AETG00000000 & $\begin{array}{l}\text { SRX101661, } \\
\text { SRX119986, } \\
\text { SRX118783 }\end{array}$ & 49997 & 710605 & $\begin{array}{c}\text { Salmonella enterica subsp. } \\
\text { enterica serovar Montevideo } \\
\text { str. 556150-1 }\end{array}$ \\
\hline 216 & 216_Black_Pepper_2 & SEEM460 & AETH00000000 & SRX101666 & 50021 & 710607 & $\begin{array}{c}\text { Salmonella enterica subsp. } \\
\text { enterica serovar Montevideo } \\
\text { str. } 609460\end{array}$ \\
\hline 217 & 217_Drain_Swab & SEEM020 & AETI00000000 & $\begin{array}{l}\text { SRX103943, } \\
\text { SRX103942, } \\
\text { SRX118784, } \\
\text { SRX119444 }\end{array}$ & 50023 & 710608 & $\begin{array}{c}\text { Salmonella enterica subsp. } \\
\text { enterica serovar Montevideo } \\
\text { str. 507440-20 }\end{array}$ \\
\hline 219 & 219_Red_Pepper_1 & SEEM6152 & AETJ00000000 & SRX103944 & 51379 & 710609 & $\begin{array}{c}\text { Salmonella enterica subsp. } \\
\text { enterica serovar Montevideo } \\
\text { str. } 556152\end{array}$ \\
\hline 220 & 220_Clinical_NC_3 & SEEM0077 & AETK00000000 & SRX103945 & 51381 & 710610 & $\begin{array}{c}\text { Salmonella enterica subsp. } \\
\text { enterica serovar Montevideo } \\
\text { str. MB101509-0077 }\end{array}$ \\
\hline 221 & 221_Clinical_NC_2 & SEEM0047 & AETL00000000 & $\begin{array}{l}\text { SRX103946, } \\
\text { SRX118785, } \\
\text { SRX119987 }\end{array}$ & 51383 & 710611 & $\begin{array}{c}\text { Salmonella enterica subsp. } \\
\text { enterica serovar Montevideo } \\
\text { str. MB102109-0047 }\end{array}$ \\
\hline 222 & 222_Clinical_NC_5 & SEEM0055 & AETM00000000 & $\begin{array}{l}\text { SRX103951, } \\
\text { SRX119988, } \\
\text { SRX118786 }\end{array}$ & 51385 & 710612 & $\begin{array}{c}\text { Salmonella enterica subsp. } \\
\text { enterica serovar Montevideo } \\
\text { str. MB110209-0055 }\end{array}$ \\
\hline 223 & 223_Clinical_NC_1 & SEEM0052 & AETN00000000 & $\begin{array}{l}\text { SRX103952, } \\
\text { SRX119989, } \\
\text { SRX118787 }\end{array}$ & 51387 & 710613 & $\begin{array}{c}\text { Salmonella enterica subsp. } \\
\text { enterica serovar Montevideo } \\
\text { str. MB111609-0052 }\end{array}$ \\
\hline 224 & 224_Clinical_OH_2 & SEEM3312 & AETO00000000 & SRX103953 & 51389 & 710614 & $\begin{array}{c}\text { Salmonella enterica subsp. } \\
\text { enterica serovar Montevideo } \\
\text { str. } 2009083312\end{array}$ \\
\hline 225 & 225_Clinical_OH_1 & SEEM5258 & AETP00000000 & SRX103954 & 51391 & 710615 & $\begin{array}{c}\text { Salmonella enterica subsp. } \\
\text { enterica serovar Montevideo } \\
\text { str. } 2009085258\end{array}$ \\
\hline 227 & 227_Pistachio_1 & SEEM1156 & AETQ00000000 & $\begin{array}{l}\text { SRX103955, } \\
\text { SRX118788 }\end{array}$ & 51393 & 710616 & $\begin{array}{c}\text { Salmonella enterica subsp. } \\
\text { enterica serovar Montevideo } \\
\text { str. } 315731156\end{array}$ \\
\hline 228 & 228_Clinical_CT* & SEEM5278 & AHHS00000000 & SRX105767 & 62845 & 754302 & $\begin{array}{c}\text { Salmonella enterica subsp. } \\
\text { enterica serovar Montevideo } \\
\text { str. CT_02035278 }\end{array}$ \\
\hline 229 & 229_Pepper_Salami_2_CT* & SEEM5318 & АНHТ00000000 & $\begin{array}{l}\text { SRX105768, } \\
\text { SRX118789 }\end{array}$ & 62847 & 754303 & $\begin{array}{c}\text { Salmonella enterica subsp. } \\
\text { enterica serovar Montevideo } \\
\text { str. CT_02035318 }\end{array}$ \\
\hline 230 & 230_Pepper_Salami_1_CT* & SEEM5320 & AHHU00000000 & $\begin{array}{l}\text { SRX105769, } \\
\text { SRX119990, } \\
\text { SRX118790 }\end{array}$ & 62849 & 754304 & $\begin{array}{c}\text { Salmonella enterica subsp. } \\
\text { enterica serovar Montevideo } \\
\text { str. CT_02035320 }\end{array}$ \\
\hline 233 & 233_Calabrese_Salami_CT* & SEEM5321 & AHHV00000000 & $\begin{array}{l}\text { SRX105770, } \\
\text { SRX118791 }\end{array}$ & 51967 & 754305 & $\begin{array}{c}\text { Salmonella enterica subsp. } \\
\text { enterica serovar Montevideo } \\
\text { str. CT_02035321 }\end{array}$ \\
\hline 235 & $\stackrel{235 \_}{\text {Salami_Packaging_CT* }}$ & SEEM5327 & AHHW00000000 & SRX105771 & 51973 & & $\begin{array}{c}\text { Salmonella enterica subsp. } \\
\text { enterica serovar Montevideo } \\
\text { str. CT_02035327 }\end{array}$ \\
\hline
\end{tabular}


Table 1 List of isolates sequenced for comparison. (Continued)

\begin{tabular}{|c|c|c|c|c|c|c|c|}
\hline 236 & 236_Clinical_IA & SEEM9199 & AETR00000000 & SRX105772 & 51975 & 710618 & $\begin{array}{c}\text { Salmonella enterica subsp. } \\
\text { enterica serovar Montevideo } \\
\text { str. IA_2009159199 }\end{array}$ \\
\hline 237 & 237_Lunch_Meat_IA_1 & SEEM8282 & AETS00000000 & $\begin{array}{l}\text { SRX103956, } \\
\text { SRX118793, } \\
\text { SRX119445 }\end{array}$ & 51979 & 710619 & $\begin{array}{c}\text { Salmonella enterica subsp. } \\
\text { enterica serovar Montevideo } \\
\text { str. IA_2010008282 }\end{array}$ \\
\hline 238 & 238_Lunch_Meat_IA_3 & SEEM8283 & AETT00000000 & $\begin{array}{l}\text { SRX103957, } \\
\text { SRX118793, }\end{array}$ & 51981 & 710620 & $\begin{array}{c}\text { Salmonella enterica subsp. } \\
\text { enterica serovar Montevideo } \\
\text { str. IA_2010008283 }\end{array}$ \\
\hline 239 & 239_Lunch_Meat_IA_2 & SEEM8284 & AETU00000000 & SRX103958 & 51983 & 710621 & $\begin{array}{c}\text { Salmonella enterica subsp. } \\
\text { enterica serovar Montevideo } \\
\text { str. IA_2010008284 }\end{array}$ \\
\hline 240 & 240_Lunch_Meat_IA_4 & SEEM8285 & AETV00000000 & SRX103959 & 51985 & 710622 & $\begin{array}{c}\text { Salmonella enterica subsp. } \\
\text { enterica serovar Montevideo } \\
\text { str. IA_2010008285 }\end{array}$ \\
\hline 241 & 241_Lunch_Meat_IA_6* & SEEM8286 & NA & $\begin{array}{l}\text { SRX105773, } \\
\text { SRX105774 }\end{array}$ & 51987 & 754308 & $\begin{array}{c}\text { Salmonella enterica subsp. } \\
\text { enterica serovar Montevideo } \\
\text { str. IA_2010008286 }\end{array}$ \\
\hline 242 & 242_Lunch_Meat_IA_5 & SEEM8287 & AETW00000000 & SRX103960 & 51989 & 710623 & $\begin{array}{c}\text { Salmonella enterica subsp. } \\
\text { enterica serovar Montevideo } \\
\text { str. IA_2010008287 }\end{array}$ \\
\hline 349 & 349_Pomona* & SEEPO729 & AHIA00000000 & SRX105896 & 61431 & 754430 & $\begin{array}{c}\text { Salmonella enterica subsp. } \\
\text { enterica serovar Pomona str. } \\
\text { ATCC } 10729\end{array}$ \\
\hline 397 & 237_Colony_1* & $\begin{array}{l}\text { resequence of } \\
\text { FDA237 colony } 1\end{array}$ & NA & SRX105897 & 51979 & 710619 & $\begin{array}{c}\text { Salmonella enterica subsp. } \\
\text { enterica serovar Montevideo } \\
\text { str. IA_2010008282 }\end{array}$ \\
\hline 398 & 237_Colony_2* & $\begin{array}{l}\text { resequence of } \\
\text { FDA237 colony } 2\end{array}$ & NA & SRX105898 & 51979 & 710619 & $\begin{array}{c}\text { Salmonella enterica subsp. } \\
\text { enterica serovar Montevideo } \\
\text { str. IA_2010008282 }\end{array}$ \\
\hline 399 & 237_Colony_3* & $\begin{array}{l}\text { resequence of } \\
\text { FDA237 colony } 3\end{array}$ & NA & SRX105899 & 51979 & 710619 & $\begin{array}{c}\text { Salmonella enterica subsp. } \\
\text { enterica serovar Montevideo } \\
\text { str. IA_2010008282 }\end{array}$ \\
\hline 400 & 237_Colony_4_Rep_1* & $\begin{array}{l}\text { resequence of } \\
\text { FDA237 colony } 4\end{array}$ & NA & SRX105900 & 51979 & 710619 & $\begin{array}{c}\text { Salmonella enterica subsp. } \\
\text { enterica serovar Montevideo } \\
\text { str. IA_2010008282 }\end{array}$ \\
\hline 401 & 400_Colony_4_Rep_2* & $\begin{array}{l}\text { resequence } 1 \text { of } \\
\text { FDA237/FDA400 } \\
\text { colony } 4\end{array}$ & NA & SRX105901 & 51979 & 710619 & $\begin{array}{c}\text { Salmonella enterica subsp. } \\
\text { enterica serovar Montevideo } \\
\text { str. IA_2010008282 }\end{array}$ \\
\hline 402 & 400_Colony_4_Rep_3* & $\begin{array}{l}\text { resequence } 2 \text { of } \\
\text { FDA237/FDA400 } \\
\text { colony } 4\end{array}$ & NA & SRX105902 & 51979 & 710619 & $\begin{array}{l}\text { Salmonella enterica subsp. } \\
\text { enterica serovar Montevideo } \\
\text { str. IA_2010008282 }\end{array}$ \\
\hline 403 & 400_Colony_4_Rep_4* & $\begin{array}{l}\text { resequence } 3 \text { of } \\
\text { FDA237/FDA400 } \\
\text { colony } 4\end{array}$ & NA & SRX105903 & 51979 & 710619 & $\begin{array}{c}\text { Salmonella enterica subsp. } \\
\text { enterica serovar Montevideo } \\
\text { str. IA_2010008282 }\end{array}$ \\
\hline 515 & 237_1st_Round_Passage* & $\begin{array}{l}\text { serial } \\
\text { resequencing } \\
\text { FDA237 plate 1st } \\
\text { round }\end{array}$ & NA & SRX105904 & 51979 & 710619 & $\begin{array}{c}\text { Salmonella enterica subsp. } \\
\text { enterica serovar Montevideo } \\
\text { str. IA_2010008282 }\end{array}$ \\
\hline 516 & 237_2nd_Round_Passage ${ }^{*}$ & $\begin{array}{l}\text { serial } \\
\text { resequencing } \\
\text { FDA237 plate } \\
\text { 2nd round }\end{array}$ & NA & SRX105905 & 51979 & 710619 & $\begin{array}{c}\text { Salmonella enterica subsp. } \\
\text { enterica serovar Montevideo } \\
\text { str. IA_2010008282 }\end{array}$ \\
\hline 517 & 237_3rd_Round_Passage* & $\begin{array}{l}\text { serial } \\
\text { resequencing } \\
\text { FDA237 plate } \\
\text { 3rd round }\end{array}$ & NA & SRX105906 & 51979 & 710619 & $\begin{array}{c}\text { Salmonella enterica subsp. } \\
\text { enterica serovar Montevideo } \\
\text { str. IA_2010008282 }\end{array}$ \\
\hline 518 & 237_4th_Round_Passage ${ }^{*}$ & $\begin{array}{l}\text { serial } \\
\text { resequencing } \\
\text { FDA237 plate } \\
\text { 4th round }\end{array}$ & NA & SRX105907 & 51979 & 710619 & $\begin{array}{c}\text { Salmonella enterica subsp. } \\
\text { enterica serovar Montevideo } \\
\text { str. IA_2010008282 }\end{array}$ \\
\hline
\end{tabular}


Table 1 List of isolates sequenced for comparison. (Continued)

\begin{tabular}{|c|c|c|c|c|}
\hline NA & Schwarzengrund_1 & SASA & СР001127 & $\begin{array}{c}\text { Salmonella enterica subsp. } \\
\text { enterica serovar } \\
\text { Schwarzengrund str. } \\
\text { CVM19633 }\end{array}$ \\
\hline NA & Schwarzengrund_2 & SASB & ABEJ01000001 & $\begin{array}{l}\text { Salmonella enterica subsp. } \\
\text { enterica serovar } \\
\text { Schwarzengrund str. SL480 }\end{array}$ \\
\hline NA & Javiana & SEJ & ABEH00000000 & $\begin{array}{c}\text { Salmonella enterica subsp. } \\
\text { enterica serovar Javiana str. } \\
\text { GA_MM04042433 }\end{array}$ \\
\hline
\end{tabular}

Entries include the FDA sample number, a simplified tree label, locus tags as well as various identifiers from the Genome BioProjects of these draft genomes. New accession and short read archive numbers are noted by an asterisk in the column entitled "Tree Label". All other accession numbers were published previously [5].

retained multiple identical PFGE patterns to the spicedmeat outbreak strains and were isolated from a variety of foods unassociated with this outbreak such as pistachios, chicken, Italian cheese, and several fishes from Indo-China. It is important to note that all of the

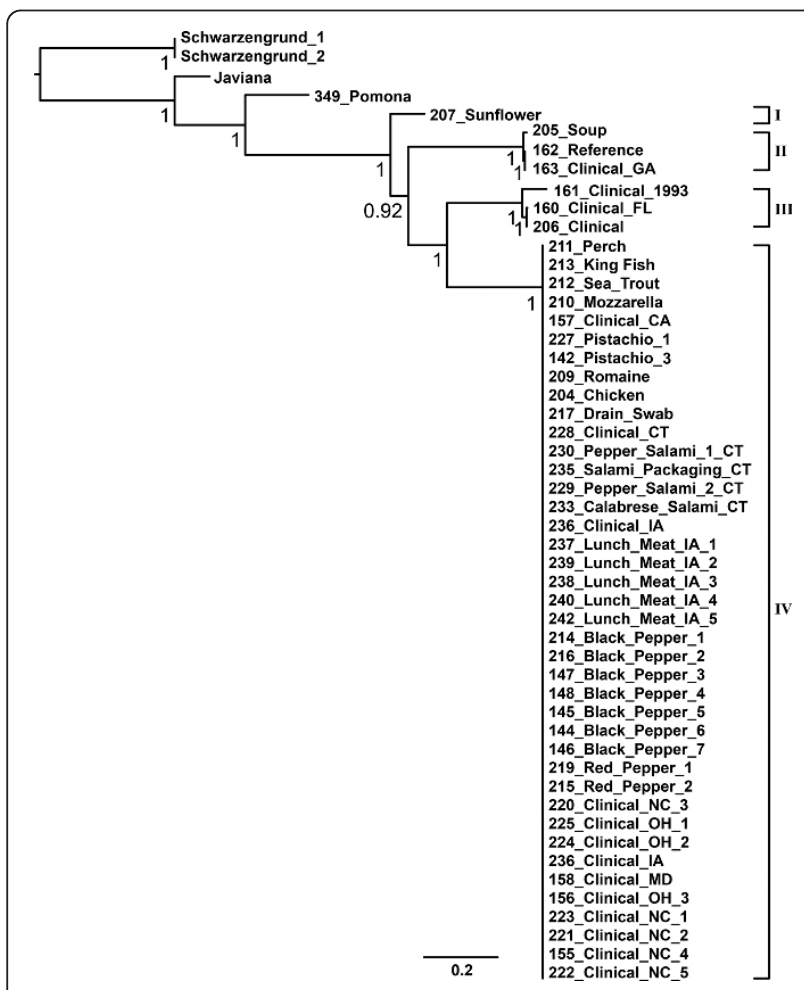

Figure 1 Phylogenetic diversity of Salmonella Montevideo based on a GARLI analysis of 72,063 variable SNP sites of which 63,987 were identified as parsimony informative. The tree was rooted with four outgroups including S. Schwarzengrund, S. Pomona, and S. Javiana. Terminal names correspond to samples in Table 1. The numbers at the base of each node are bootstrap scores with most of the deepest nodes supported at 100\%. The scale bar units are nucleotide substitutions per site and these are proportional across the branch lengths with longer branches having greater substitutions. S. Montevideo strains partitioned into four clades designated I-IV. clinical isolates included here (Figure 3) were collected in association with the spiced-meat outbreak event.

Results from the phylogenetic analysis provided several important findings relevant to the phylogenetic differentiation of clonal $S$. Montevideo strains (Figure 3). First, in contrast to the serovar tree presented in Figure 1 , SNP diversity within this highly clonal sub-lineage of $S$. Montevideo was markedly lower as expected, less than 500 informative SNPs defined the entire tree. However, the resultant likelihood tree partitioned this clone into six distinct groups of isolates that were separated from neighboring groups by less than 100 parsimony informative SNPs each. Additionally, isolates associated previously with the spiced-meat outbreak clustered together in a group separate and distinct from groups of closely related $S$. Montevideos unassociated with this contamination event (e.g., pistachios/B, chicken/D, and fish/A). From a phylogenetic perspective, clades $\mathrm{E}$ and $\mathrm{F}$ appear to capture the scope of the outbreak. There are several reasons that support this partition. Clinical isolates (i.e., CT clinical isolates) associate closely with a drain strain from the facility forming clade E (Figure 3) and from contaminated spices collected at the facility along with a host of clinicals from several states (i.e., IA, $\mathrm{MD}, \mathrm{NC}$, and $\mathrm{OH}$ ) nearly all of which were indistinguishable from the food isolates (clade F, Figure 3). It is also noteworthy that clade F retained a subgroup of NC isolates that were separated from the other food and clinical spiced-meat strains by just a few SNPs. However, these isolates are clear monophyletic members of clade $F$, one of the two outbreak clades, and may have emerged from the base of this clade through microevolutionary change. Whatever the final explanation, NGS analysis coupled with a comparative phylogenetic approach not only fully differentiated this clone of $S$. Montevideo, but also provided high resolution genetic information that effectively delimited the scope of the outbreak event, affirming its potential as a powerful tool for supporting molecular epidemiologic investigation of clonal outbreaks of non-typhoidal Salmonella [5]. 
Table 2 Pairwise distances (no. of nucleotide differences) and Standard Errors (SE) for the major groups shown in Figure 1.

\begin{tabular}{|c|c|c|c|c|c|c|c|}
\hline & Schwarzengrund & Javiana & Pomona & Clade I & Clade II & Clade III & Clade IV \\
\hline Schwarzengrund & $23(2.9)$ & & & & & & \\
\hline Javiana & $25700(70)$ & NA & & & & & \\
\hline Pomona & $27600(130)$ & 17800 ( 73) & NA & & & & \\
\hline Clade I & $32500(85)$ & 23700 ( 92) & $22700(120)$ & NA & & & \\
\hline Clade II & 33000 ( 98) & $27100(110)$ & $25900(73)$ & $17600(120)$ & $499(8.5)$ & & \\
\hline Clade III & $32800(130)$ & 26100 ( 59) & $27700(110)$ & 18400 ( 78) & $22200(44)$ & $2718(43)$ & \\
\hline Clade IV & $34300(150)$ & $26500(110)$ & $24600(150)$ & $19300(170)$ & $23800(130)$ & $19300(130)$ & $13.5(2.0)$ \\
\hline
\end{tabular}

Distances were calculated using the concatenated alignment of 63,987 informative SNPs that estimates the diversity between S. Schwarzendgrund, S. Javiana, S. Pomona and the major clades of $S$. Montevideo observed.

SNP variation within the $S$. Montevideo spiced-meat clone was nearly two logs lower than what was noted for total intra-serovar diversity. Nevertheless, the signature SNPs that delineated these six subgroups (A-F) originated from various regions around the $S$. Montevideo genome and included a variety of genes assigned to diverse cellular functions including metabolism, DNA synthesis and repair, transport and uptake, virulence, and stress response. A list of 43 genes from which the SNPS that characterize $S$. Montevideo clade IV were derived is provided in Table 3. A representative SNP from each of these genes is also provided in the table along with the subgroup that it defines and its bp coordinates. Thirty of these genes

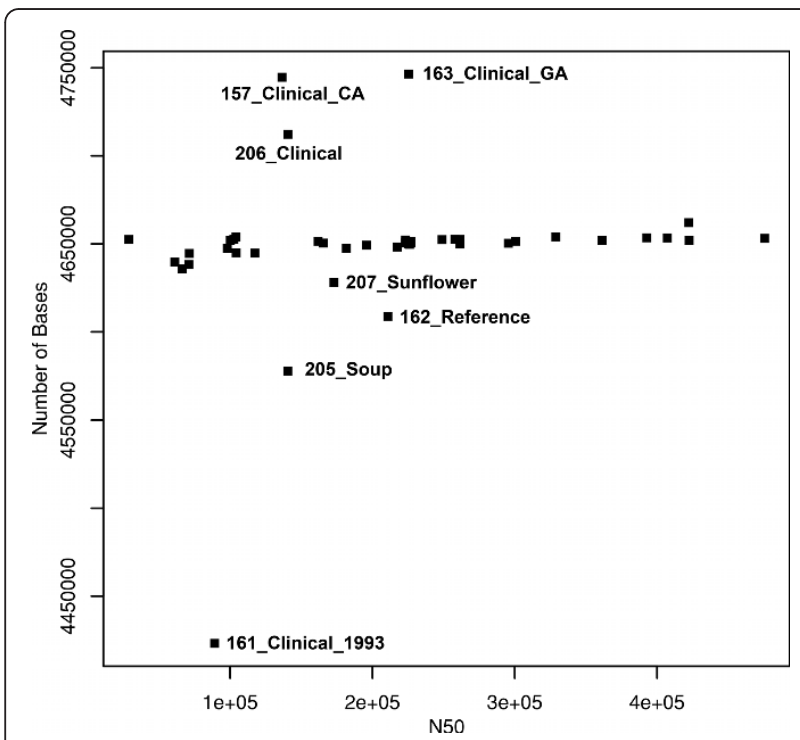

Figure 2 Genome size variation and estimated N50 sizes within Salmonella Montevideo draft genome sequences. The estimated N50 value is a rough estimate of the quality and coverage of the draft genomes which was sequenced to approximately 15-20x coverage. The N50 value represents the average contig size after assembly with the Newbler software. Isolate names correspond to samples in Table 1. Genome length ranged from less than $4.45 \mathrm{mbp}$ to about $4.75 \mathrm{mbp}$, with most isolates approximately $4.65 \mathrm{mbp}$ in size (unlabeled boxes). Only the larger or smaller genomes are listed. were annotated previously with assigned names and functions; however, 13 additional regions that provided signature SNPs are hypothetical and, as such, are crossreferenced by locus tags only. It is notable that a partial and select set of SNPS from 25 of these 43 genes are nonsynonymous, and of the 14 SNPs in Table 3 that cluster together two or more $S$. Montevideo subgroups in Figure 3 , all but three are protein- altering in nature. These data are intriguing given an NGS report documenting positive selection among a significant subset of core genes in adapted Salmonella enterica serovars [30].

Although the majority of isolates composing the spiced-meat $S$. Montevideo clone generally exhibited a common genome length, one isolate from California ( $S$. Montevideo 157_Clinical_CA) retained a noticeably larger genome than other members of this lineage (Figure 2 ). In addition to being separated from other $S$. Montevideos associated with the spiced-meat contamination event by nine phylogenetically informative SNPs (Figure $4 \mathrm{~A})$, comparative analysis revealed the presence of a 100 kb insertion with substantial homology to Enterobacterial phage D6. Since phage D6 was incomplete in GenBank (No. AY753669), a MAUVE comparison to another homologous relative, phage P1 (No. NC_005856), was helpful in suggesting that this may represent a D6-like phage insertion into contig 104 in this particular $S$. Montevideo genome. Based on the known length of phage D6, this particular insertion in $S$. Montevideo strain 157 accounts for observed variation between this genome $(\sim 4.75 \mathrm{Mb})$ and the other spicedmeat $S$. Montevideo genomes reported here $(\sim 4.65$ $\mathrm{Mb})$. Moreover, this finding underscores the utility of whole-genome scanning technologies for placing the source of size polymorphisms between otherwise homogeneous strains of Salmonella.

NGS reveals phylogenetic discordance of hyperdiscriminatory PFGE enzymes in an S. Montevideo outbreak cluster

The extent of phylogenetically congruent clustering between NGS and other conventional subtyping 


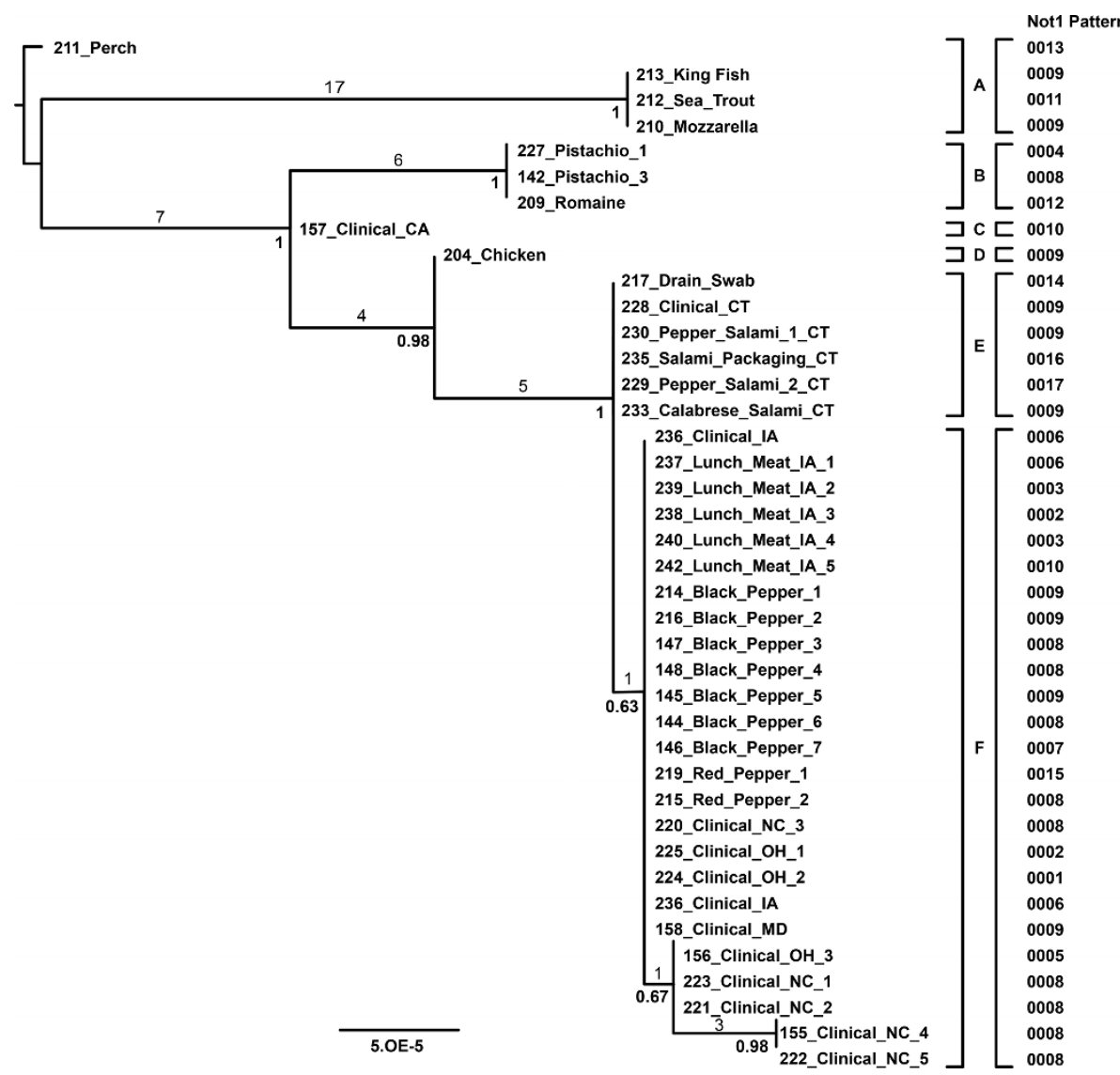

Figure 3 Phylogenetic diversity and relationships among a single $S$. Montevideo clone. GARLI phylogenetic analysis of the outbreak isolates was performed on a set of 43 concatenated ORFs containing informative SNPs (Table 3). Terminal names, scale bar, branch lengths and bootstrap scores are as in Figure 1. Numbers above the branches represent unique SNPs that define these internal branches. The phylogenetic analysis reported here partitions the $S$. Montevideo clone into 6 lineages (A-F) and expands upon a previous tree [5] with the inclusion of 5 more strains and the noted expansion of outbreak strains into clade E. To the right of the tree, each isolate is labeled with the Not1 pattern that was determined using PFGE with each unique number identifying a new Not1 pattern.

technologies such as PFGE, MLST, or MLVA is largely unknown for most serovars of S. enterica. Congruence is important in accessing the ability of subtyping methods to accurately assign genetic relatedness among closely related strains, such as those implicated in foodborne outbreak events [31]. Previous studies from our laboratory and elsewhere have demonstrated enhanced discrimination and accuracy for PFGE in assigning genetic relatedness of some Salmonella and E. coli O157:H7 strains by concatenating up to six different restriction enzyme patterns into single cluster analyses $[6,10,31,32]$.

The availability of whole-genome sequences of Salmonella, such as $S$. Montevideo, enables a comparison between the conclusions of an epidemiological investigation and the linked clusters obtained from comparative genomics of the suspect isolates. One can also examine the patterns of linkage based on other genetic tools to the epidemiological evidence such as the discriminatory power of several non-conventional PFGE enzymes in the highly homogeneous group of $S$. Montevideos described above. After generating PFGE patterns for the six enzymes reported previously as part of the published concatenated PFGE protocol for non-typhoidal Salmonella in a previous study of $S$. Enteritidis and $S$. Typhimurium [6], we overlaid individual enzyme patterns onto the $S$. Montevideo NGS tree presented in Figure 3 and assessed congruence (i.e. agreement) in cluster assignments between the two methods. Owing to the extreme genetic homogeneity among these strains, four of the six enzymes (i.e., XbaI, BlnI, SpeI, and SfiI) revealed identical PFGE patterns for all 40 of the $S$. Montevideo isolates included in the whole-genome tree. Moreover, the predominant pacI pattern varied in only one isolate (S. Montevideo 211) from Chinese Perch. In contrast, however, NotI, an enzyme reported previously as having a high discriminatory index for $S$. Typhimurium and $S$. Enteritidis [6], yielded 18 distinct patterns among the $40 \mathrm{~S}$. Montevideos comprising this outbreak 
Table 343 Variable genes found within a clonal lineage of Salmonella Montevideo.

\begin{tabular}{|c|c|c|c|c|c|c|c|}
\hline Gene & LT Locus & Drain Locus & Nuc & $\mathrm{AA}$ & Position & Clade & Feature \\
\hline lig & STM2427 & SEEM020_00085 & $\mathrm{C} / \mathrm{T}$ & T & 1974 & $b$ & DNA ligase, NAD-dependent \\
\hline perM & STM2493 & SEEM020_00410 & $\mathrm{C} / \mathrm{T}$ & A & 1034 & $d, e, f$ & permease PerM \\
\hline aroB & STM3486 & SEEM020_01090 & $\mathrm{C} / \mathrm{T}$ & V/A & 488 & $\begin{array}{l}b, c, d, \\
e, f\end{array}$ & shikimate kinase I \\
\hline yrfl & STM3498 & SEEM020_01145 & $\mathrm{C} / \mathrm{T}$ & $\mathrm{T} / \mathrm{I}$ & 353 & $\begin{array}{l}b, c, d, \\
e, f\end{array}$ & heat shock protein \\
\hline gntK & STM3542 & SEEM020_01330 & $\mathrm{G} / \mathrm{A}$ & $\mathrm{H} / \mathrm{Q}$ & 93 & a1 & 1) gluconate transporter $\mathrm{GntU}, 2$ ) shikimate kinase \\
\hline dppA & STM3630 & SEEM020_01925 & $\mathrm{C} / \mathrm{T}$ & $\mathrm{H}$ & 282 & a1 & dipeptide transport protein \\
\hline tolB & STM0748 & SEEM020_01960 & $\mathrm{G} / \mathrm{T}$ & $A / S$ & 64 & a1 & tolB protein precursor \\
\hline citG & STM0619 & SEEM020_04239 & $\mathrm{C} / \mathrm{T}$ & $R / C$ & 181 & $\begin{array}{l}b, c, d, \\
e, f\end{array}$ & triphosphoribosyl-dephospho-CoA synthase \\
\hline citF & STM0621 & SEEM020_04249 & $\mathrm{C} / \mathrm{T}$ & V/A & 602 & $\begin{array}{l}b, c, d, \\
e, f\end{array}$ & citrate lyase alpha chain \\
\hline \multirow[t]{7}{*}{$y d f z$} & STM1509 & SEEM020_04749 & $\mathrm{G} / \mathrm{A}$ & $P$ & 174 & $b$ & putative selenium-binding protein $\mathrm{YdfZ}$ \\
\hline & STM1546 & SEEM020_04939 & $\mathrm{C} / \mathrm{T}$ & L & 1473 & $d, e, f$ & 1) putative multidrug efflux protein, 2) hypothetical protein \\
\hline & SeSA_A1664 & SEEM020_05139 & $\mathrm{C} / \mathrm{T}$ & L & 667 & a1 & LysR substrate binding domain protein \\
\hline & STM1627 & SEEM020_05529 & $\mathrm{C} / \mathrm{T}$ & T & 543 & a1 & alcohol dehydrogenase class III \\
\hline & STM1628 & SEEM020_05534 & $\mathrm{T} / \mathrm{G}$ & $L / R$ & 155 & a1 & putative cytoplasmic protein \\
\hline & STM1671 & SEEM020_05759 & $\mathrm{A} / \mathrm{C}$ & V & 122 & a1 & putative regulatory protein \\
\hline & STM1856 & SEEM020_06993 & $\mathrm{G} / \mathrm{T}$ & $\begin{array}{l}\text { E/ } \\
\text { Stop }\end{array}$ & 316 & & putative cytoplasmic protein \\
\hline flic & STM1959 & SEEM020_07518 & T/A & $\mathrm{N} / \mathrm{K}$ & 723 & a1 & phase 1 flagellin \\
\hline uhpA & STM3790 & SEEM020_08264 & $A / G$ & I & 60 & a1 & 1) sensor histidine kinase UhpB, 2)transcriptional regulatory protein UhpA \\
\hline \multirow[t]{2}{*}{ nuol } & STM2318 & SEEM020_09061 & $\mathrm{C} / \mathrm{T}$ & $\mathrm{F}$ & 291 & $\mathrm{f} 2$ & NADH dehydrogenase I \\
\hline & STM4534 & SEEM020_10120 & $\mathrm{C} / \mathrm{T}$ & AN & 14 & b & putative transcriptional regulator \\
\hline ytfG & STM4401 & SEEM020_10825 & $\mathrm{C} / \mathrm{T}$ & $S / F$ & 503 & f3 & conserved hypothetical protein \\
\hline \multirow[t]{2}{*}{ yjeM } & STM4345 & SEEM020_11085 & $\mathrm{C} / \mathrm{T}$ & L & 1179 & a1 & putative APC family amino-acid transport protein \\
\hline & STM4261 & SEEM020_11575 & $\mathrm{G} / \mathrm{A}$ & $\mathrm{V} / \mathrm{I}$ & 4684 & & putative inner membrane protein \\
\hline araD & STM0101 & SEEM020_12590 & C/A & $\mathrm{Q} / \mathrm{K}$ & 466 & b & L-ribulose-5-phosphate 4-epimerase \\
\hline \multirow[t]{3}{*}{ araB } & STM0103 & SEEM020_12600 & $\mathrm{G} / \mathrm{A}$ & L & 702 & $e, f$ & L-ribulokinase \\
\hline & STM3260 & SEEM020_13557 & G/A & V/M & 70 & b & PTS family galactitol-specific enzyme ॥C \\
\hline & SeD_A3648 & SEEM020_13697 & $A / G$ & $\mathrm{D} / \mathrm{G}$ & 263 & $d, e, f$ & hypothetical protein \\
\hline pduV & STM2056 & SEEM020_14356 & $\mathrm{G} / \mathrm{A}$ & $\mathrm{D} / \mathrm{G}$ & 353 & $\begin{array}{l}b, c, d, \\
e, f\end{array}$ & propanediol utilization protein \\
\hline orf408 & STM1382 & SEEM020_15066 & $\mathrm{G} / \mathrm{A}$ & T/A & 1096 & a1 & putative regulatory protein, deoR family \\
\hline ydiA & STM1348 & SEEM020_15231 & $\mathrm{C} / \mathrm{T}$ & $\mathrm{F}$ & 126 & $\begin{array}{l}b, c, d, \\
e, f\end{array}$ & putative inner membrane protein \\
\hline envE & STM1242 & SEEM020_15746 & $\mathrm{T} / \mathrm{C}$ & $\mathrm{I} / \mathrm{T}$ & 446 & a1 & EnvE \\
\hline \multirow[t]{2}{*}{$y c f x$} & STM1220 & SEEM020_15941 & $\mathrm{C} / \mathrm{T}$ & G & 24 & $d, e, f$ & $\mathrm{~N}$-acetylglucosamine kinase \\
\hline & STM4097 & SEEM020_16375 & $\mathrm{G} / \mathrm{A}$ & $\mathrm{S} / \mathrm{N}$ & 119 & a1 & putative outer membrane lipoprotein \\
\hline \multirow[t]{2}{*}{ uvrD } & STM3951 & SEEM020_17067 & $\mathrm{G} / \mathrm{A}$ & $\mathrm{G} / \mathrm{E}$ & 2111 & $f 2$ & DNA helicase II \\
\hline & STM2404 & SEEM020_17529 & $\mathrm{G} / \mathrm{T}$ & $\mathrm{A} / \mathrm{S}$ & 394 & b & putative chloride channel permease \\
\hline recB & STM2994 & SEEM020_17950 & $\mathrm{G} / \mathrm{A}$ & $S / G$ & 901 & $d, e, f$ & exodeoxyribonuclease $\mathrm{V}$ \\
\hline$s t d B$ & STM3028 & SEEM020_18130 & $\mathrm{C} / \mathrm{T}$ & L & 2433 & $\mathrm{f} 2$ & putative outer membrane usher protein \\
\hline yqjl & STM3215 & SEEM020_19095 & $C / A$ & $\mathrm{H} / \mathrm{N}$ & 562 & $e, f$ & $\begin{array}{l}\text { 1) transcriptional regulator }(\mathrm{PadR}), 2) \text { family methyl-accepting chemotaxis } \\
\text { protein II }\end{array}$ \\
\hline \multirow[t]{2}{*}{ ybhk } & STM0801 & SEEM020_19330 & $\mathrm{G} / \mathrm{A}$ & L & 618 & a1 & conserved hypothetical protein \\
\hline & STM0818 & SEEM020_19410 & $\mathrm{G} / \mathrm{T}$ & $A / S$ & 277 & $e, f$ & $\begin{array}{l}\text { 1) putative ABC-type multidrug transport system, 2) membrane permease } \\
\text { predicted cation efflux pump }\end{array}$ \\
\hline yliD & STM0851 & SEEM020_19565 & $\mathrm{T} / \mathrm{C}$ & W/R & 760 & & putative $A B C$ transporter inner membrane component \\
\hline invE & STM2897 & SEEM020_21151 & $C / G$ & $\mathrm{~L} N$ & 757 & f & invasion protein \\
\hline уејM & STM2228 & SEEM020_21392 & $\mathrm{G} / \mathrm{A}$ & $A / E$ & 395 & a1 & putative hydrolase of alkaline phosphatase superfamily \\
\hline
\end{tabular}

Variable genes are listed by their Genbank abbreviated and full name (feature) and by the blast locus hit to either a reference isolate LT2 or the Drain swab isolate. A representative nucleotide change observed within each gene is listed as well as whether this caused an AA change and to which phylogenetic group it was associated with from Figure $3(\mathrm{~A}-\mathrm{F})$. These SNPs were the most useful for the spiced meat outbreak investigation and will be useful for both targeted resequencing efforts and for rapid subtyping methods for traceback of future $S$. Montevideo investigation and diagnosis. 


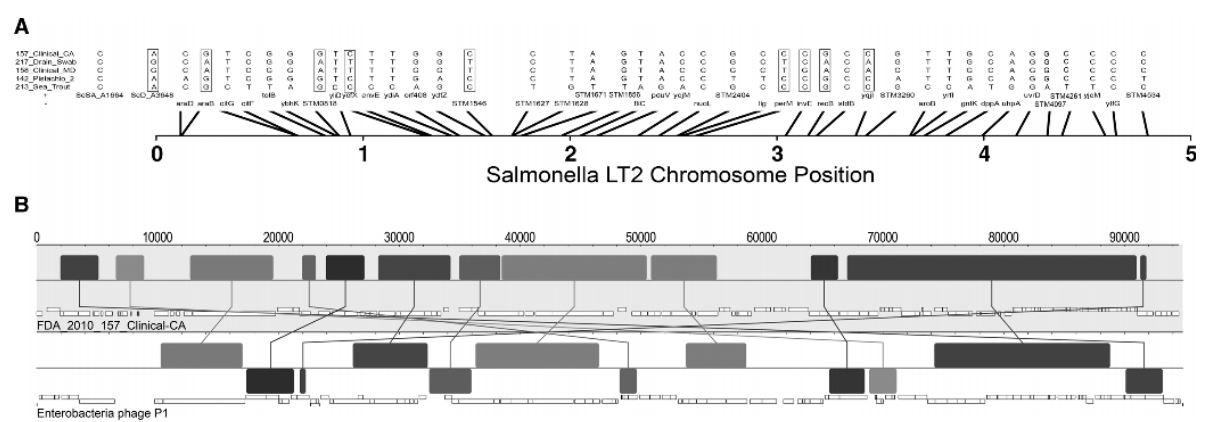

Figure 4 NGS discovery of unique SNPs and insertional genetic attributes found in a highly homogeneous strain of S. Montevideo from California (157_Clinical_CA). (A) Isolate names correspond to samples in Table 1, and gene names correspond to the ORFs containing informative SNPs among a single S. Montevideo outbreak clone in Table 3. A representative nucleotide site observed across 5 isolates is listed for each ORF. ORFs are mapped against a reference of S. Typhimurium strain LT2 with lines going to approximate chromosomal positions relative to the reference (numbers in mbp). (B) A comparative MAUVE analysis of isolate 157_Clinical_CA revealed the presence of a $100 \mathrm{~kb}$ insertion with homology to Enterobacterial phage D6. Here we compared the isolate to another more complete homologous relative, phage P1 to document the insertion site. Graphic is standard MAUVE format showing putative genes as boxes with arrows documenting insertions and rearrangements. Forward and reverse strands are on opposite sides of the mid-line.

cluster. Albeit, side-by-side comparison of NotI pattern variants with NGS subgroups delineated in the clone tree revealed evidence for homoplasy (i.e., convergent pattern evolution) for this enzyme (Figure 3). That is, NotI patterns FDA.NotI.009, -.010. and -.011 were represented by $S$. Montevideo isolates from different subgroups in the tree suggesting that these patterns emerged independently in distinct places during the recent evolution of these isolates. As an example, pattern FDA.NotI.009 is represented twice in group A, once in group $B$ and $D$, three times in group $E$, and four times in group $F$. Thus, while the concatenation of multiple PFGE enzyme data sets may permit a more accurate clustering of closely related Salmonellae, these data sound a cautionary note when attempting to cluster outbreak strains based on any single PFGE enzyme, including highly polymorphic ones such as NotI.

\section{Biological, laboratory, and technical replicates of Salmonella Montevideo support reproducibility of NGS applications}

As the power of NGS is realized in public health settings, deployment of the technology is expected to become more commonplace. Thus, it is important to further evaluate the technology, addressing questions concerning expected variation between closely related strains, background variation, and SNP variation that may arise during sub-culturing possibly obscuring an accurate molecular epidemiological analysis of isolates associated with contamination or outbreak events. That is, does variation arise in subsequent passages of an isolate and, if so, can phylogenetic analysis overcome the potentially misleading background noise associated with this level of sensitivity? We investigated this issue by sequencing to $\sim 15 \times$ coverage $11 S$. Montevideo isolates derived from clinical-food matches associated with the 2009 spiced-Italian style meat contamination event, such that isolates were taken from the patient as well as the suspected corresponding food vehicle that sickened that particular patient. Specifically, we included seven matching $S$. Montevideo isolates from a single clinical/food source in Iowa and five isolates from a single clinical/ food source in Connecticut. Additionally, we sequenced a single $S$. Montevideo food isolate (237_Lunch_Meat) for separate passages (4X) (i.e., biological variation), separate colonies from the same passage $(4 X)$ (i.e, laboratory variation), and separate sequencing reactions from a single colony $(4 \mathrm{X})$ (i.e, Roche technical variation). Passages were conducted as follows: the initial sample was taken from frozen stock and plated on a TSA plate. Once plated it was incubated overnight at 37 degrees $C$. This was followed by Day 2 were sample was taken from the Day 1 overnight plate to inoculated the day 2 TSA plate. This day 2 plate was incubated overnight at 37 degrees C. Day 3 sample was taken from the Day 2 overnight plate and inoculated a day 3 TSA plate which was then incubated overnight at 37 degrees $C$. Day 4 sample was from the Day 3 overnight plate to inoculated the day 4 TSA plate and incubated overnight at 37 degrees $C$. After each plate was grown overnight, growth was taken from that plate and grown up a broth culture for DNA extraction of each of the genomic samples. Also, all samples were not single colony isolates for any of these plates. All passages and samples are representative cultures from the full plate and not just single colony.

Whole-genome sequencing yielded an alignment of approximately $4.5 \mathrm{mbps}$ for downstream analysis. A total of 639 variable SNP sites were identified of which 23 were found to be parsimony informative among the 
validation isolates described above. However, once the data filter was applied to the remaining SNPs (i.e., elimination of SNPs in homopolymeric tracts, adjacent to assembly breakpoints, and duplicated in other lineages), only a single informative SNP at position 3,823,524 was found remaining which was stable in the original $S$. Montevideo isolate (237_Lunch_Meat_IA_1) and all of its downstream genomes derived from subsequent passages, colonies, and DNA samples of this one strain (Table 4). We also searched for SNPs using the proprietary run Mapping software from Roche and found the SNP corresponding to position $3,823,524$ in the WGS alignment (results not shown).

As expected, these laboratory-generated isolates were indistinguishable in a phylogenetic analysis with the single parsimony informative SNP separating the 237_Lunch_Meat_IA_1 S. Montevideo isolate series from the other Iowa matching clinical-food isolates (Figure 5). Among the replicate genomes, only two sequences, genomes from S. Montevideo isolate 237 from the second and third round passages, retained actual SNP variation that emerged on the tree. That is, save for a single nucleotide difference present in the

Table 4 Variable SNP calls discovered with resequencing and results after these were passed through our data filter.

\begin{tabular}{|c|c|}
\hline Position & Description \\
\hline 204781 & Missing after MUSCLE \\
\hline 255578 & Homopolymer (8 T/A) \\
\hline 355131 & Missing after MUSCLE \\
\hline 756435 & Homopolymer (9 C/G) \\
\hline 1070504 & SNP in Gap \\
\hline 1097814 & Homopolymer (9 T/A) \\
\hline 1179704 & Homopolymer (7 T/A) \\
\hline 1205130 & Good (but ambiguous after looking at assembly) \\
\hline 1368882 & Missing after MUSCLE \\
\hline 1642240 & Missing after MUSCLE \\
\hline 1693620 & Homopolymer (6 T/A) \\
\hline 1713322 & Missing after MUSCLE \\
\hline 1806153 & Homopolymer (6 T/A) \\
\hline 2087876 & Missing after MUSCLE \\
\hline 2354057 & Homopolymer (6 T/A) \\
\hline 2545225 & Missing after MUSCLE \\
\hline 3193883 & Homopolymer (7 T/A) \\
\hline 3823524 & Good \\
\hline 4257557 & Homopolymer (8 T/A) \\
\hline 4545198 & SNP in Gap \\
\hline 4545878 & Duplicated in other Salmonella (Elongation Factor Tu) \\
\hline 4546413 & SNP in Gap \\
\hline 4548105 & $23 S$ rRNA \\
\hline
\end{tabular}

Details of the variation arising from resequencing are listed including the variable site location, a description of the variant, the nucleotide change and corrections during our rapid data analysis pipeline.

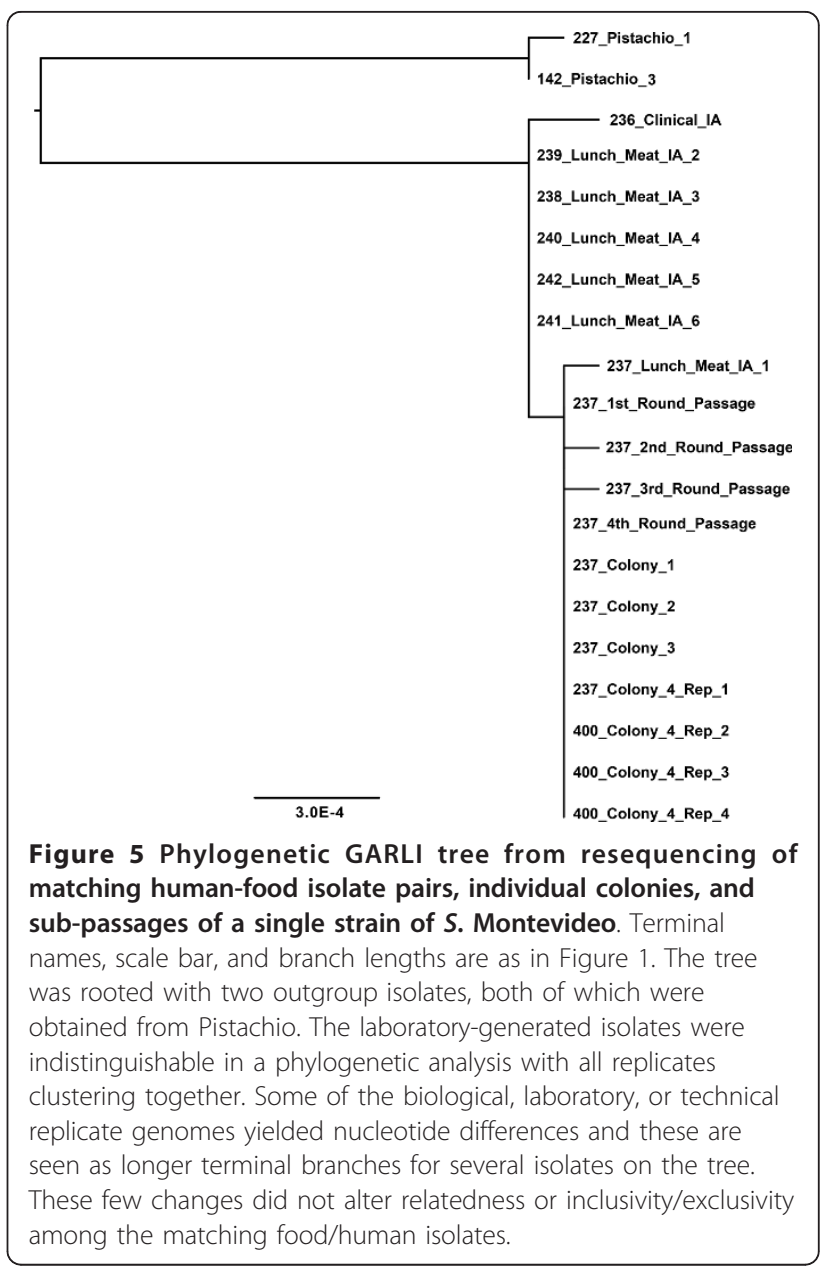

original 237 sample and two of the four downstream passages (i.e., 237-second round and 237-third round), none of the additional biological, laboratory, or technical replicate genomes yielded nucleotide differences after alignment and quality filtration. It is important to note that these few changes did not alter relatedness or inclusivity/exclusivity among the matching food/ human isolates. Rather, the only structural difference in the tree to arise from these three changes was in the form of branch length for the individual isolates affected. Additionally, it is noteworthy that, in the larger outbreak clone tree, the Connecticut and Iowa matching isolates were both phylogenetically inseparable from their sister isolates, and collectively, both strain sets sorted squarely among the spiced-meat food, environmental, and clinical isolates associated with the same contamination event (Figure 3). These findings indicate that when NGS data are quality filtered and inspected carefully using inclusivity/exclusivity criteria, the resultant stable and informative SNP data can be used effectively to phylogenetically partition closely related isolates of S. enterica (i.e., S. 
Montevideo). Consistent with this find, a bolus of successful applications is now accruing [17-20].

\section{NGS provides discovery for development of novel MLVA targets}

Aside from its emerging and direct role in highly homogeneous $S$. enterica outbreaks, it is important to recall the important function of NGS for augmenting conventional detection, identification, and subtyping methods development. Currently, several rapidly evolving regions of the Salmonella chromosome are under investigation for their utility for enhanced subtyping of highly homogeneous Salmonella strains associated with foodborne outbreaks. Specifically, select VNTRs (variable number tandem repeats) in the genomes of Salmonella and E. coli have been targeted to develop markers and probes for MLVA (multi-locus VNTR analysis), a rapid and sensitive subtyping method that fingerprints the genomes of closely related strains based on size polymorphism of VNTR sequences [33,34].

Since MLVA protocols are developed at the serovar level for Salmonella, very few are available save for the most significant and widely studied Salmonellae (i.e., S. Typhimurium and $S$. Enteritidis). Here, using our NGS alignments only, we identified a polymorphic VNTR region within $S$. Montevideo that may serve in the development of a MLVA protocol for this important foodborne serovar as well (Table 5). The locus was identified within a cell division gene $(f t s \mathrm{~N})$ and delineates the major $S$. Montevideo lineages represented in our NGS serovar tree in Figure 1. Moreover, this finding illustrates the importance of providing NGS data from multiple strains and multiple serovars in order to foster the identification of additional MLVA loci to support rapid subtyping protocols for Salmonella serovars of public health significance.

\section{Discussion}

Here, we reported the use of NGS technology for describing the phylogenetic diversity of $S$. Montevideo, a significant serovar of $S$. enterica involved in numerous outbreaks and product recalls http://www.cdc.gov/nci$\mathrm{dod} / \mathrm{dbmd} / \mathrm{phlisdata/Salmonella.htm \# 2009.} \mathrm{Moreover,}$ we have applied informative substitutions from these genomes to further ascertain phylogenetic relatedness among a highly homogeneous $S$. Montevideo clone, of which some strains were associated with a recent spiced-meat outbreak event in the U.S last year. In this instance, the investigatory utility of NGS became apparent as the unusual genetic homogeneity among both outbreak associated and non-associated $S$. Montevideo strains could not be resolved unambiguously with more conventional genotyping approaches. Comparative genomic molecular epidemiology produced hundreds of SNP differences across distinct lineages of $S$. Montevideo and even provided broad size differences among the most distantly diverged strains of this serovar. Among the $S$. Montevideos populating clade IV in the serovar tree, nearly all shared common pulsotypes for $X b a \mathrm{I}$ and $B \ln \mathrm{I}$ as well as for several additional enzymes including SpeI, $S f i$, and PacI. NGS combined with phylogenetic analysis, however, was able to delineate the scope of contamination by differentiating those strains associated with the spiced-meat outbreak from strains epidemiologically unrelated to this event despite the remarkable genetic identity linking these two strain sets. Given the extraordinary resolution that NGS provides-resolution best described as "nanotyping", it is not surprising that, when Salmonella isolates with divergent PFGE patterns are sequenced using NGS technology, the resultant alignments typically yield thousands of SNP differences.

For $S$. Montevideo, four disparate lineages of strains were observed (i.e., clades I-IV, Figure 1). One lineage, in particular (i.e., clade I in Figure 1), was characterized by a single isolate from sunflower, and it remained unclear as to whether the long branch distinguishing this isolate was due to changes that accumulated more recently from laboratory passages or whether observed variation in this strain accrued in a natural setting. Surprisingly, this sunflower isolate clustered with several $S$. Montevideos recently isolated from pet treats and a pet treat-manufacturing environment underscoring the potential risk associated with this and the other discrete lineages of this serovar http://www.fda.gov/NewsEvents/ Newsroom/PressAnnouncements/ucm197700.htm. That is, it appears that foodborne contamination events can emerge from any of these diverged $S$. Montevideo lineages which are able to survive in foods and cause illness in humans. Clinical isolates were found in each of the major and separate lineages of $S$. Montevideo tested (Figure 1 Clades I, II, III, and IV). Moreover, such observations enforce the notion that in addition to these attributes, the risk to public health also stems from a particular Salmonella lineage simply gaining the opportunity to contaminate the human or animal food supply, rather than any one $S$. Montevideo lineage being more fit to persist in foods over any other.

Separation, based on SNP distances, among the four phyletic lineages of $S$. Montevideo reported here rivaled distances observed between $S$. Montevideo and other distinct Salmonella subspecies I serovars including $S$. Pomona, S. Javiana, and S. Schwarzengrund. Such remarkable interclade divergences suggests that the four major lineages of $S$. Montevideo diverged early in the evolution of this serovar, and each appears to have evolved largely independent of the others, an evolutionary pattern consistent with a hypothesis of unique host/ niche adaptation for the separate lineages and 
Table 5 Polymorphic VNTR discovery found within a cell division gene (ftsN) in S. Montevideo using NGS applications.

\begin{tabular}{|c|c|}
\hline 160_Clinical_FL & TGCGTTTGAGCCCACTGCTGCTGCTGCTGCTGCTGCTGCTGCTGCTGCTGCTGCTGCGCCT \\
\hline 206_Clinical & _________CTGCTGCTGCTGCTGCTGCTGCTGCGCCT \\
\hline 161_Clinical_1993 & _-_CTGCTGCTGCTGCTGCTGCTGCTGCGCCT \\
\hline 207_Sunflower & $\begin{array}{l}\text { TGCGTITGAGCCCA-_-_-_- } \\
\text { CTGCTGCTGCTGCTGCTGCGCCT }\end{array}$ \\
\hline 205_Soup & $\begin{array}{l}\text { TGCGTTTGAGCCCA-_-- } \\
\text { CTGCTGCTGCTGCTGCGCCT }\end{array}$ \\
\hline 162_Reference & $\begin{array}{l}\text { TGCGTTTGAGCCCA-_- - } \\
\text { CTGCTGCTGCTGCTGCGCCT }\end{array}$ \\
\hline 163_Clinical_GA & $\begin{array}{l}\text { TGCGTTTGAGCCCA-_- - } \\
\text { CTGCTGCTGCTGCTGCGCCT }\end{array}$ \\
\hline 221_Clinical_NC_2 & ——_—_CTGCTGCTGCTGCTGCTGCTGCTGCTGCTGCTGCGCCT \\
\hline 223_Clinical_NC_1 & __—__CTGCTGCTGCTGCTGCTGCTGCTGCTGCTGCTGCGCCT \\
\hline 222_Clinical_NC_5 & —_CTGCTGCTGCTGCTGCTGCTGCTGCTGCTGCTGCGCCT \\
\hline 220_Clinical_NC_3 & ____CTGCTGCTGCTGCTGCTGCTGCTGCTGCTGCTGCGCCT \\
\hline 217_Drain_Swab & —____CTGCTGCTGCTGCTGCTGCTGCTGCTGCTGCTGCGCCT \\
\hline 155_Clinical_NC_4 & ___CTGCTGCTGCTGCTGCTGCTGCTGCTGCTGCTGCGCCT \\
\hline 227_Pistachio_1 & —_CTGCTGCTGCTGCTGCTGCTGCTGCTGCTGCTGCGCCT \\
\hline 212_King Fish & _____CTGCTGCTGCTGCTGCTGCTGCTGCTGCTGCTGCGCCT \\
\hline 204_Chicken & ____CCTGCTGCTGCTGCTGCTGCTGCTGCTGCTGCTGCGCCT \\
\hline 147_Black_Pepper3 & —_CTGCTGCTGCTGCTGCTGCTGCTGCTGCTGCTGCGCCT \\
\hline 148_Black_Pepper4 & _—CTGCTGCTGCTGCTGCTGCTGCTGCTGCTGCTGCGCCT \\
\hline 142_Pistachio_2 & ———_CTGCTGCTGCTGCTGCTGCTGCTGCTGCTGCTGCGCCT \\
\hline 224_Clinical_OH_2 & ______CTGCTGCTGCTGCTGCTGCTGCTGCTGCTGCTGCGCCT \\
\hline 216_Black_Pepper2 & _____CTGCTGCTGCTGCTGCTGCTGCTGCTGCTGCTGCGCCT \\
\hline 215_Red_Pepper_2 & —_CTGCTGCTGCTGCTGCTGCTGCTGCTGCTGCTGCGCCT \\
\hline 158_Clinical_MD & _-_CTGCTGCTGCTGCTGCTGCTGCTGCTGCTGCTGCGCCT \\
\hline 225_Clinical_OH_1 & _—CTGCTGCTGCTGCTGCTGCTGCTGCTGCTGCTGCGCCT \\
\hline 228_Clinical_CT & _-CTGCTGCTGCTGCTGCTGCTGCTGCTGCTGCTGCGCCT \\
\hline 229_Salami_2_CT & _- CTGCTGCTGCTGCTGCTGCTGCTGCTGCTGCTGCGCCT \\
\hline 230_Salami_1_CT & _-__CTGCTGCTGCTGCTGCTGCTGCTGCTGCTGCTGCGCCT \\
\hline 233_Salami_CT & _—CTGCTGCTGCTGCTGCTGCTGCTGCTGCTGCTGCGCCT \\
\hline 235_Salami_CT & —_CTGCTGCTGCTGCTGCTGCTGCTGCTGCTGCTGCGCCT \\
\hline 214_Black_Pepper1 & —_CTGCTGCTGCTGCTGCTGCTGCTGCTGCTGCTGCGCCT \\
\hline 213_Sea_Trout & _-__C CTGCTGCTGCTGCTGCTGCTGCTGCTGCTGCTGCGCCT \\
\hline 219_Red_Pepper_1 & _-CTGCTGCTGCTGCTGCTGCTGCTGCTGCTGCTGCGCCT \\
\hline 156_Clinical_OH_3 & _- C CTGCTGCTGCTGCTGCTGCTGCTGCTGCTGCTGCGCCT \\
\hline 209_Romaine & ____CTGCTGCTGCTGCTGCTGCTGCTGCTGCTGCTGCGCCT \\
\hline 237_Meat_IA_1 & —_-CTGCTGCTGCTGCTGCTGCTGCTGCTGCTGCTGCGCCT \\
\hline 238_Meat_IA_3 & _—_—CTGCTGCTGCTGCTGCTGCTGCTGCTGCTGCTGCGCCT \\
\hline 239_Meat_IA_2 & -_CCTGCTGCTGCTGCTGCTGCTGCTGCTGCTGCTGCGCCT \\
\hline 240_Meat_IA_4 & _-___CTGCTGCTGCTGCTGCTGCTGCTGCTGCTGCTGCGCCT \\
\hline 242_Meat_IA_5 & _—CTGCTGCTGCTGCTGCTGCTGCTGCTGCTGCTGCGCCT \\
\hline 211_Perch & -_—————_CTGCTGCTGCTGCTGCTGCTGCTGCTGCTGCTGCGCCT \\
\hline 210_Mozzarella & TGCGTTTGAGCCCA_——_—_———_——CTGCTGCTGCTGCTGCTGCTGCTGCTGCTGCTGCGCCT \\
\hline 236_Clinical_IA & TGCGTTTGAGCCCA________________CTGCTGCTGCTGCTGCTGCTGCTGCTGCTGCTGCGCCT \\
\hline 157_Clinical_CA & TGCGTTTGAGCCCA_______________CTGCTGCTGCTGCTGCTGCTGCTGCTGCTGCTGCGCCT \\
\hline 144_Black_Pepper6 & 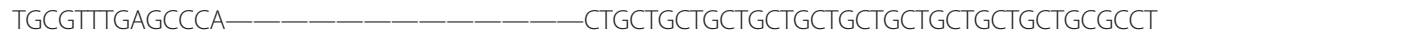 \\
\hline 145_Black_Pepper5 & 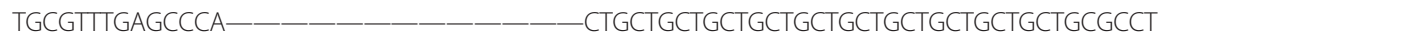 \\
\hline 146_Black_Pepper7 & _______CTGCTGCTGCTGCTGCTGCTGCTGCTGCTGCTGCGCCT \\
\hline
\end{tabular}


sublineages that compose this serovar. This thesis is further supported by an examination of variable genes and SNPs that define various lineages of isolates within $S$. Montevideo clade IV. That is, 25 of 43 select informative SNPs (Table 3) defining subgroups within this clade were non-synonymous. Additionally, $78 \%$ of the representative informative SNPs clustering together two or more $S$. Montevideo subgroups were also found to be polymorphic. These data are reminiscent of a previous report by Soyer et al., [30] which noted a potentially significant role for positive selection based on an unusual proportion of non-synonymous substitutions across the genomes of several host-adapted serovars including $S$. Cholerasuis, $S$. Typhimurium, and the agent of Typhus, serovar $S$. Typhi (28). Taken together, these data signal $S$. Montevideo as a potentially niche-adapted and evolutionarily diverse serovar among the subspecies I Salmonellae, a conclusion additionally supported by an extraordinary ecological range and natural persistence in diverse environments (e.g., S. Montevideo has been found associated with spices, produce, poultry, beef and porcine commodities to name but a few).

The results from the genome validation study reported here also merit discussion. After collecting over $50 \mathrm{mbp}$ of finished bacterial sequence for multiple downstream passages, colonies, and DNA preparations of a single $S$. Montevideo isolate, it was clear that NGS had provided sufficiently stable data to conclude that no single potential source of variability tested (i.e., biological, laboratory or technical) was capable of altering phylogenetic conclusions uncovered during the comparative genomic investigation. That is, despite the detection of three substitutions among serially passaged genomes from a single $S$. Montevideo source, no re-sequenced replicate conflicted with our phylogenetic conclusions here or for strains included in a previously published letter defining an $S$. Montevideo spiced-meat outbreak cluster [5]. Rather, it is clear that phylogenetic approaches are providing rational and highly reproducible analytical outcomes for high-resolution NGS data pipelines and appear to be sufficiently robust for reconstructing strain relatedness based on the hundreds and sometimes thousands of informative changes that amass from a single NGS experiment.

Global deployment of NGS technology as a direct investigatory tool has already proven to be highly successful to the public health community. In addition to the NGS application described here for one non-typhoidal Salmonella serovar, NGS has provided extraordinary insight into case studies involving: (i) traceback of tuberculosis infections in Canada [20]; (ii) high-resolution evolutionary linkage of global clones of Salmonella Typhi [19]; and (iii) identification of the origins of the Haitian Cholera outbreak [17] as a few examples. It is important to note, however, that NGS data can provide additional utility for development of other subtyping methods. The MLVA locus presented here is one example of how NGS can serve as a genomic "compass" in seeking out VNTR regions with sufficient rates of change to develop custom MLVA assays for other important Salmonella serovars beyond S. Typhimurium and $S$. Enteritidis. Additionally, as shared NGS public health databases expand, many outbreak swarms will be defined by even more rapid and efficient re-sequencing protocols that target a subset of informative SNPs relative to the differentiation of a specific outbreak clone of pathogenic bacteria.

We would like to caution that the results reported here, while extremely encouraging, do not supplant the need for independent laboratory validations to establish SOPs for their particular platforms and chemistry and kits. Such validations may include the adoption of standard practices that have worked so well with past genetic testing, including $\mathrm{CE}$ methods that can more easily target and validate variable sites identified by whole genome sequencing and downstream phylogenetic analyses. Clearly, given the evolutionary rates governing nucleotide change among enteric bacteria combined with the risk of intrinsic polymerase error in the sequencing process itself, each step of the pathway, from isolate collection and template preparation to the sequencing reactions, could potentially spawn artifactual variability. A careful assessment of all of these sources of variation should provide more confidence for molecular epidemiological applications including the detection and scope of disease outbreak clusters.

\section{Conclusions}

These results underscore the power of NGS, when coupled with phylogenetic analysis, to illuminate the genetic and evolutionary diversity of important serovars of Salmonella enterica along with the associated epidemiological pathways surrounding specific outbreak strains [17-20]. It appears that, at least in the case of Salmonella, the natural variation observed between strains is both stable and sufficient to allow for high resolution traceback of food and clinical isolates. It will be interesting to see whether ample genomic diversity can drive similar outcomes in other problematic taxa and highly clonal Salmonella serotypes. Moreover, NGS will provide the phylogenetic context on which to interpret other facile subtyping approaches that focus on more rapidly evolving genetic markers such as MLVA, rep-PCR, and CRISPRs [6-11,35] and will provide a novel suite of SNPs that will be critical to partitioning common Salmonella outbreak strains. In public health arenas, NGS strain "nanotyping" holds the potential to revolutionize the manner in which responses to 
outbreaks are managed. At a minimum, we see a future where NGS methods are brought to bare on the most difficult questions involving this enteric pathogen including direct application in foodborne outbreak cases in combination with other time-tested methods of epidemiologic investigation.

\section{Methods}

\section{Data collection and analysis pipeline methods}

Roche 454. GS Titanium NGS technology was employed in this study. This platform provided longer read lengths relative to other sequencers and a relatively shorter time to raw sequence [23]. Longer read lengths resulted in fewer contigs for draft assembly and aided in a more accurate placement of phage and plasmid sequences, both of which are commonplace among the group I salmonellae. All S. Montevideo isolates were draft shotgun sequenced using this platform and included 47 total isolates of $S$. Montevideo including 40 with PFGE patterns matching the spiced-meat outbreak (Figure 1, lineage IV) and 7 with unrelated PFGE patterns (Figure 1, lineages I-III). Additionally, 11 genomic replicates were sequenced for the validation experiment, including multiple colonies from the same plate $(n=4)$, multiple passages of an isolate $(\mathrm{n}=4)$, and independent sequencing experiments $(n=4)$ from the same DNA source (Figure 5). Each isolate was run on a quarter of a titanium plate that produced roughly 250,000 reads per draft genome and coverage from $13 \times$ to $18 \times$. Draft sequences for 34 of the 47 isolates were previously released as part of an outbreak case study [5] to test earlier hypotheses regarding the delimiting of foodborne contamination events.

De novo assemblies were created using the Roche Newbler (v 2.3) software package and the resulting contigs were annotated using NCBI's Prokaryotic Genomes Automatic Annotation Pipeline [PGAAP, [36]]. Phylogenetically informative SNP sites were identified using two independent alignment methods: 1) clustering of annotated open reading frames (ORFs) using reciprocal best Basic Local Alignment Search Tool [BLAST, http:// blast.ncbi.nlm.nih.gov/Blast.cgi] hits with a $70 \%$ sequence identity setting followed by alignment with Multiple Sequence Comparison by Log-Expectation [MUSCLE, [37]], and 2) multiple genome alignment of WGS contigs using Mauve [38]. Duplicated genes were eliminated from all ORF clusters. The Mauve and ORF cluster alignments were then screened to find non-gap phylogenetically informative nucleotide positions (i.e. minor allele count $\geq 2$ ). Informative positions from all ORF clusters and Mauve outputs were identical in the annotated protein coding regions. Informative positions for isolates in the outbreak cluster were manually checked to eliminate SNPs in homopolymers and repetitive elements. In this way, roughly $10-15$ percent of the draft genome is filtered out, but the remaining SNPs are highly reproducible, providing sufficient variation for an informed molecular epidemiology interpretation [23].

Phylogenetic analysis of the clonal S. Montevideo data set including multiple serovars was performed on a set of 55,032 concatenated informative SNPs which encompasses the diversity within $S$. Montevideo. Approximately $99 \%$ of the sites in the 5 MB Salmonella genomes are phylogenetically uninformative and eliminating them dramatically reduces computation time and memory requirements. Phylogenetic analysis of the outbreak isolates was performed on the set of 43 concatenated ORFs containing informative SNPs. In all cases, phylogenetic trees were constructed using GARLI [39] under the maximum likelihood criterion. The phylogenetic tree in Figure 1 was constructed using GARLI under the GTR + gamma model of nucleotide evolution. The phylogenetic trees in Figure 3 and 5 were constructed using GARLI under the HKY + gamma model of nucleotide evolution.

The other related Salmonella including S. Schwarzendgrund and $S$. Javiana were taken from genbank (Table 1). S. Pomona was sequenced like the $S$. Montevideo isolates with an FDA ID number. One comparative genomics analysis suggested that $S$. Schwarzendgrund and $S$. Javiana are closely related [27] and our independent analyses, not shown, also would include $S$. Montevideo and $S$. Pomona in this cluster so we include all of these as outgroups.

We use the resultant phylogenetic trees to make hypotheses about the evolution of the $S$. Montevideo subtypes and the outbreak strains and to aid in investigation source tracking. We use these evolutionary hypotheses to identify reliable diagnostic nucleotide motifs (SNPs, rearrangements, and gene presences) for the identification of outbreak strains and for understanding the mechanisms that drive the outbreak occurrences. These methods allow both the rapid characterization of the genomes of foodborne pathogenic bacteria and can help identify the source of contamination of the food supply.

\section{Availability of data and cultures}

All NCBI $S$. Montevideo genomes are linked to Bioproject 61937 which lists the new accession numbers AESR00000000-AESY00000000, AHIA00000000 and AHHT00000000 - AHHW00000000. Cultures included in this study are also available upon request to anyone with valid paper work and clearances. Please direct any queries to our strain curator Dwayne Roberson, at Dwayne.Roberson@fda.hhs.gov. 


\section{Acknowledgements}

We thank the NCBI rapid annotation pipeline team, Bill Klimke, Dmitry Dernovoy, Stacy Ciufo, Ruth Timme, Kathleen O'Neill, Azat Badretdin and Tatiana Tatusova, for key genome annotation services, and Charlie Wang and Guojie Cao for expert data collection. We acknowledge David Weingaertner for excellent graphical support, and would also like to thank Donald Zink, John Guzewich, Sherri McGarry, Mickey Parrish, Kathy Gombas, Roberta Wagner, Donald Kraemer, and Michael Landa from CFSAN-FDA for program support and for important epidemiological and investigatory insights as well as important discussion of our manuscript. We would also like to acknowledge our FDA-ORA regional field laboratories in Denver, Arkansas, and Atlanta for providing key outbreak and historical isolates along with the Iowa, Connecticut, North Carolina, Maryland, Ohio, California, and Rhode Island State Departments of Public Health for generous contributions of additional clinical S. Montevideo isolates. In particular, we would like to acknowledge Stacey Kinney (Connecticut Department of Health) and Mary DiMartino (lowa Department of Health) for providing key human-food matching pairs of S. Montevideo. Mark Wilson, Peter Evans, Stephanie Defibaugh-Chavez, Kurt Lienau, Peter Gerner-Smidt, and several anonymous people also provided helpful reviews. No human subjects or animals were used in this study. All authors have read the manuscript and agree to its content, subject matter, and author line order. These data are novel and have not been previously published elsewhere. Disclosure forms provided by the authors will be available with the full text of this article.

\section{Author details}

${ }^{1}$ Office of Regulatory Science, Center for Food Safety \& Applied Nutrition, U. S. Food \& Drug Administration, 5100 Paint Branch Parkway, College Park, MD 20740, USA. ${ }^{2}$ Office of Food Defense, Communications, and Emergency Response, Center for Food Safety \& Applied Nutrition, U.S. Food \& Drug Administration, 5100 Paint Branch Parkway, College Park, MD 20740, USA. ${ }^{3}$ Food \& Environment Research Agency, Sand Hutton, York, YO41 1LZ, UK.

\section{Authors' contributions}

ES and YL performed the bioinformatics analysis and analyzed the data; RS provided critical programming and bioinformatic tools; MWA, SMM, and EWB planned and conceived the experiments and co-wrote the manuscript; $\mathrm{CL}$ generated the sequencing libraries; and CEK and IS generated and analyzed the PFGE data. All authors read and approved the final manuscript.

Received: 28 September 2011 Accepted: 19 January 2012 Published: 19 January 2012

\section{References}

1. Buzby JC, Roberts T: The economics of enteric infections: human foodborne disease costs. Gastroenterology 2009, 136, 1851-62.8.

2. Mead PS, Slutsker L, Dietz V, McCaig LF, Bresee JS, Shapiro C, Griffin PM, Tauxe RV: Food-related illness and death in the United States. Emerg Infect Dis 1999, 5:607-25.

3. Maki DG: Coming to grips with foodborne infection-peanut butter, peppers, and nationwide Salmonella outbreaks. N Engl J Med 2009, 360:949-53.

4. Scallan E, Griffin PM, Angulo FJ, Tauxe RV, Hoekstra RM: Foodborne illness acquired in the United States-unspecified agents. Emerg Infect Dis 2011, 17:16-22.

5. Lienau EK, Strain E, Wang C, Cao G, Zheng J, Ottesen AR, Keys CE, Hammack TS, Musser SM, Brown EW, Allard MW, Cao G, Meng J, Stones R: Identification of a Salmonellosis Outbreak by Means of Molecular Sequencing. N Engl J Med 2011, 364:981-982.

6. Zheng J, Keys CE, Zhao S, Meng J, Brown EW: Enhanced subtyping scheme for Salmonella enteritidis. Emerg Infect Dis 2007, 13:1932-1935.

7. Fitzgerald $C$, Collins M, van Duyne S, Mikoleit M, Brown T, Fields P: Multiplex, bead-based suspension array for molecular determination of common Salmonella serogroups. J Clin Microbiol 2007, 45:3323-3334.

8. Sukhnanand S, Alcaine S, Warnick LD, Su WL, Hof J, Craver MP, McDonough P, Boor KJ, Wiedmann M: DNA sequence-based subtyping and evolutionary analysis of selected Salmonella enterica serotypes. Clin Microbiol 2005, 43:3688-3698.

9. McQuiston JR, Herrera-Leon S, Wertheim BC, Doyle J, Fields PI, Tauxe RV, Logsdon JM Jr: Molecular phylogeny of the Salmonellae: relationships among Salmonella species and subspecies determined from four housekeeping genes and evidence of lateral gene transfer events. $J$ Bacteriol 2008, 190:7060-7067.

10. Xi M, Zheng J, Zhao S, Brown EW, Meng J: An enhanced discriminatory pulsed-field gel electrophoresis scheme for subtyping Salmonella serotypes Heidelberg, Kentucky, SaintPaul, and Hadar. J Food Prot 2008, 71:2067-2072.

11. Wise MG, Siragusa GR, Plumblee J, Healy M, Cray PJ, Seal BS: Predicting Salmonella enterica serotypes by repetitive sequence-based PCR. J Microbiol Methods 2009, 76:18-24.

12. Cebula TA, Brown EW, Jackson SA, Mammel MK, Mukherjee A, LeClerc JE: Molecular applications for identifying microbial pathogens in the post-9/ 11 era. Expert Rev Mol Diagn 2005, 5:431-445.

13. Rokas A, Abbot P: Harnessing genomics for evolutionary insights. Trends Ecol Evol 2009, 24:192-200.

14. Wu D, Hugenholtz $P$, Mavromatis K, Pukall R, Dalin E, Ivanova NN, Kunin V, Goodwin L, Wu M, Tindall BJ, Hooper SD, Pati A, Lykidis A, Spring S, Anderson IJ, D'haeseleer P, Zemla A, Singer M, Lapidus A, Nolan M, Copeland A, Han C, Chen F, Cheng JF, Lucas S, Kerfeld C, Lang E, Gronow S, Chain P, Bruce D, Rubin EM, Kyrpides NC, Klenk HP, Eisen JA: A phylogeny-driven genomic encyclopaedia of Bacteria and Archaea. Nature 2009, 462:1056-1060.

15. Mardis ER: Next-generation DNA sequencing methods. Annu Rev Genomics Hum Genet 2008, 9:387-402.

16. Mardis ER: The impact of next-generation sequencing technology on genetics. Trends Genet 2008, 24:133-141.

17. Chin C-S, Sorenson J, Harris JB, Robins WP, Charles RC, Jean-Charles RR, Bullard J, Webster DR, Kasarskis A, Peluso P, Paxinos EE, Yamaichi Y, Calderwood SB, Mekalanos JJ, Schadt EE, Waldor MK: The Origin of the Haitian Cholera Outbreak strain. N Engl J Med 2010, 1056:1-10.

18. Harris SR, Feil EJ, Holden MT, Quail MA, Nickerson EK, Chantratita N, Gardete S, Tavares A, Day N, Lindsay JA, Edgeworth JD, de Lencastre H, Parkhill J, Peacock SJ, Bentley SD: Evolution of MRSA during hospital transmission and intercontinental spread. Science 2010, 327:469-474.

19. Holt KE, Parkhill J, Mazzoni CJ, Roumagnac P, Weill FX, Goodhead I, Rance R, Baker S, Maskell DJ, Wain J, Dolecek C, Achtman M, Dougan G: Highthroughput sequencing provides insights into genome variation and evolution in Salmonella Typhi. Nat Genet 2008, 40:987-993.

20. Gardy JL, Johnston JC, Ho Sui SJ, Cook VJ, Shah L, Brodkin E, Rempel S, Moore R, Zhao Y, Holt R, Varhol R, Birol I, Lem M, Sharma MK, Elwood K, Jones SJ, Brinkman FS, Brunham RC, Tang P: Whole-Genome Sequencing and Social-Network Analysis of a Tuberculosis Outbreak. N Engl J Med 2011, 364:730-739

21. Budowle B, Allard MW, Wilson MR, Chakraborty R: Forensics and mitochondrial DNA: applications, debates, and foundations. Annu Rev Genomics Hum Genet 2003, 4:119-41.

22. Handy SM, Deeds JR, Ivanova NV, Hebert PD, Hanner RH, Ormos A, Weigt LA, Moore MM, Yancy HF: A single-laboratory validated method for the generation of DNA barcodes for the identification of fish for regulatory compliance. J AOAC Int 2011, 94:201-210.

23. Margulies M, Egholm M, Altman WE, Attiya S, Bader JS, Bemben LA, Berka J, Braverman MS, Chen YJ, Chen Z, Dewell SB, Du L, Fierro JM, Gomes XV, Godwin BC, He W, Helgesen S, Ho CH, Irzyk GP, Jando SC, Alenquer ML, Jarvie TP, Jirage KB, Kim JB, Knight JR, Lanza JR, Leamon JH, Lefkowitz SM, Lei M, Li J, Lohman KL, Lu H, Makhijani VB, McDade KE, McKenna MP, Myers EW, Nickerson E, Nobile JR, Plant R, Puc BP, Ronan MT, Roth GT, Sarkis GJ, Simons JF, Simpson JW, Srinivasan M, Tartaro KR, Tomasz A, Vogt KA, Volkmer GA, Wang SH, Wang Y, Weiner MP, Yu P, Begley RF, Rothberg JM: Genome sequencing in microfabricated high-density picolitre reactors. Nature 2005, 437:376-380.

24. Gilles A, Meglecz E, Pech N, Ferreira S, Malausa T, Martin J-F: Accuracy and quality assessment of $454 \mathrm{GS}$-FLX Titanium pyrosequencing. BMC Genomics 2011, 12:245

25. Boyd EF, Wang FS, Beltran P, Plock SA, Nelson K, Selander RK: Salmonella reference collection $B$ (SARB): strains of 37 serovars of subspecies I. J Gen Microbiol 1993, 139:1125-1132.

26. Garcia-Russell N, Elrod B, Dominguez K: Stress-induced prophage DNA replication in Salmonella enterica serovar Typhimurium. Infect Genet Evol 2009, 9:889-895

27. Jacobsen A, Hendriksen RS, Aaresturp FM, Ussery DW, Friis C: The Salmonella enterica Pan-genome. Microb Ecol 2011, 62:487-504. 
28. den Bakker HC, Moreno Switt Al, Cummings CA, Hoelzer K, Degoricija L, Rodriguez-Rivera LD, Wright EM, Fang R, Davis M, Root T, SchoonmakerBopp D, Musser KA, Villamil E, Waechter H, Kornstein L, Furtado MR, Wiedmann M: A whole genome SNP based approach to trace and identify outbreaks linked to a common Salmonella enterica subsp. enterica serovar Montevideo Pulsed Field Gel Electrophoresis type. Appl Environ Microbiol 2011, doi:10.1128/AEM.06538-11.

29. Fricke WF, Mammel MK, McDermott PF, Tartera C, White DG, Leclerc JE, Ravel J, Cebula TA: Comparative genomics of 28 Salmonella enterica isolates: evidence for CRISPR-mediated adaptive sublineage evolution. J Bacteriol 2011, 193:3556-3568.

30. Soyer Y, Orsi RH, Rodriguez-Rivera LD, Sun Q, Wiedmann M: Genome wide evolutionary analyses reveal serotype specific patterns of positive selection in selected Salmonella serotypes. BMC Evol Biol 2009, 9:264.

31. Zheng J, Keys CE, Zhao S, Ahmed R, Meng J, Brown EW: Simultaneous analysis of multiple enzymes increases accuracy of pulsed-field gel electrophoresis in assigning genetic relationships among homogeneous Salmonella strains. J Clin Microbiol 2011, 49:85-94.

32. Davis MA, Hancock DD, Besser TE, Call DR: Evaluation of pulsed-field gel electrophoresis as a tool for determining the degree of genetic relatedness between strains of Escherichia coli 0157:H7. J Clin Microbiol 2003, 41:1843-1849.

33. Ramisse V, Houssu P, Hernandez E, Denoeud F, Hilaire V, Lisanti O, Ramisse F, Cavallo JD, Vernaud G: Variable number of tandem repeats in Salmonella enterica subsp. Enterica for typing purposes. J Clin Microbiol 2004, 42:5722-5730.

34. Keys C, Kemper S, Keim P: Highly diverse variable number tandem repeat loci in the E. coli 0157:H7 and 055:H7 genomes for high-resolution molecular typing. J Appl Microbiol 2005, 98:928-940.

35. Karginov FV, Hannon GJ: The CRISPR System: Small RNA-Guided Defense in Bacteria and Archaea. Molecular Cell 2010, 37:7-19.

36. Klimke W, Agarwala R, Badretdin A, Chetvernin S, Ciufo S, Fedorov B, Kiryutin B, O'Neill K, Resch W, Resenchuk S, Schafer S, Tolstoy I, Tatusova T: The National Center for Biotechnology Information's Protein Clusters Database. Nucleic Acids Res 2009, 37:D216-D223.

37. Edgar RC: MUSCLE: multiple sequence alignment with high accuracy and high throughput. Nucleic Acids Res 2004, 32:1792-1797.

38. Darling ACE, Mau R, Blatter FR, Perna NT: Mauve: multiple alignment of conserved genomic sequence with rearrangements. Genome Res 14:1394-1403.

39. Zwickl DJ: Genetic algorithm approaches for the phylogenetic analysis of large biological sequence datasets under the maximum likelihood criterion. PhD dissertation The University of Texas at Austin; 2006.

\section{Submit your next manuscript to BioMed Central and take full advantage of:}

- Convenient online submission

- Thorough peer review

- No space constraints or color figure charges

- Immediate publication on acceptance

- Inclusion in PubMed, CAS, Scopus and Google Scholar

- Research which is freely available for redistribution 